\title{
Economic Analysis of Restricting Aggregate-Surfaced Roofing Systems in Tornado-Prone Areas of the U.S.
}

\author{
Joshua Kneifel \\ Marc Levitan \\ Long Phan \\ Thomas Smith \\ David Butry \\ Douglas Thomas
}

This publication is available free of charge from: http://dx.doi.org/10.6028/NIST.TN.1930
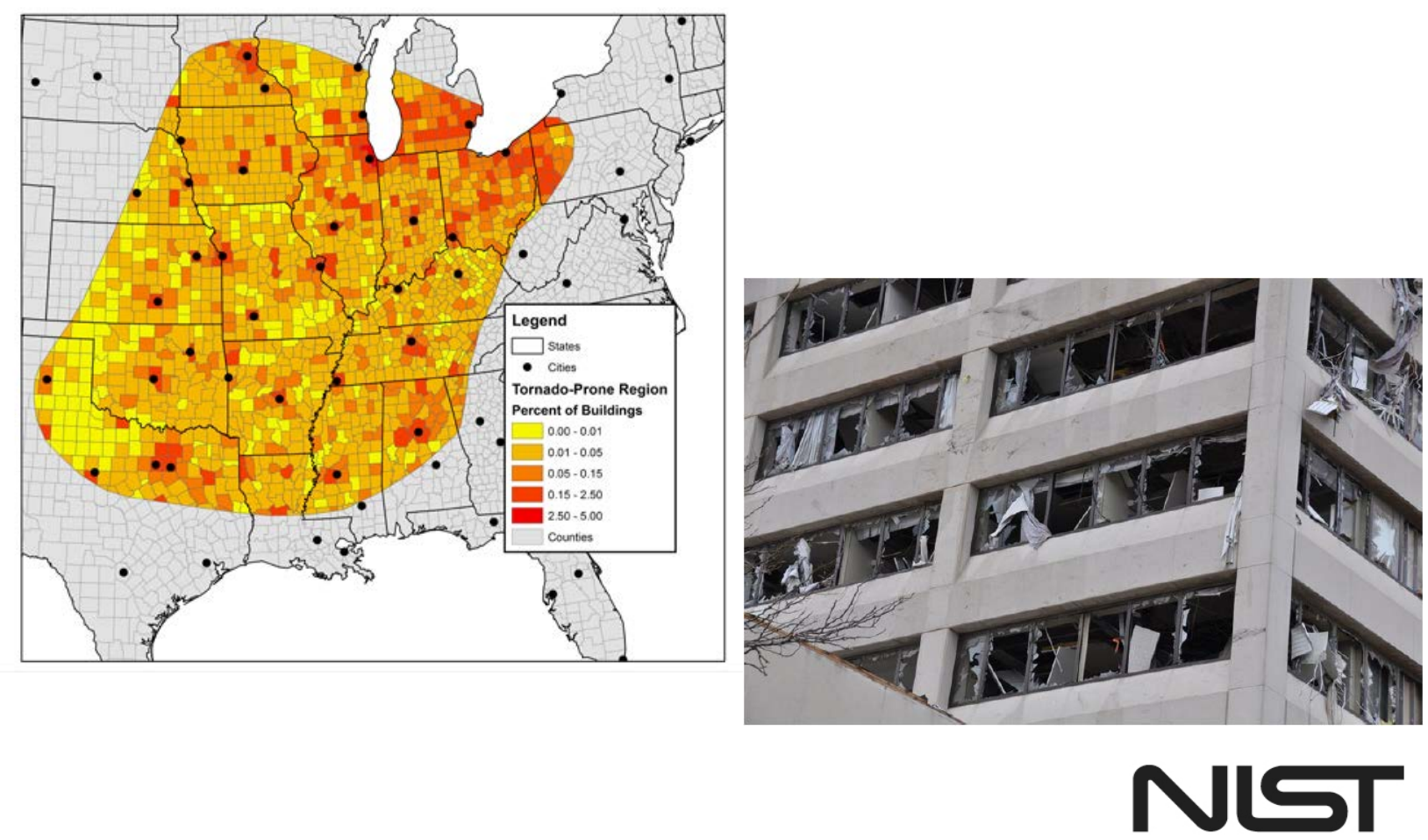

National Institute of Standards and Technology U.S. Department of Commerce 



\title{
NIST Technical Note 1930
}

\section{Economic Analysis of Restricting Aggregate-Surfaced Roofing Systems in Tornado-Prone Areas of the U.S.}

\author{
Joshua Kneifel \\ David Butry \\ Douglas Thomas \\ Applied Economics Office \\ Engineering Laboratory \\ Marc Levitan \\ Long Phan \\ Structures Group \\ Engineering Laboratory \\ Thomas Smith \\ TLSmith Consulting Inc.
}

This publication is available free of charge from:

http://dx.doi.org/10.6028/NIST.TN.1930

September 2016

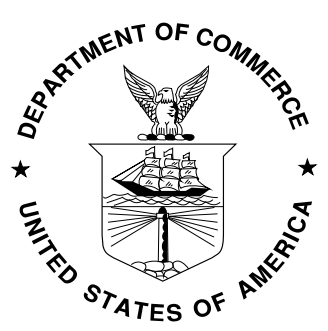

U.S. Department of Commerce Penny Pritzker, Secretary

National Institute of Standards and Technology Willie May, Under Secretary of Commerce for Standards and Technology and Director 
Certain commercial entities, equipment, or materials may be identified in this document in order to describe an experimental procedure or concept adequately. Such identification is not intended to imply recommendation or endorsement by the National Institute of Standards and Technology, nor is it intended to imply that the entities, materials, or equipment are necessarily the best available for the purpose.

National Institute of Standards and Technology Technical Note 1930 Natl. Inst. Stand. Technol. Tech. Note 1930, 41 pages (September 2016) CODEN: NTNOEF

This publication is available free of charge from: http://dx.doi.org/10.6028/NIST.TN.1930 


\begin{abstract}
Due to the significant life-safety and economic loss resulting from extreme, "low probability, high consequence” weather events such as Hurricane Katrina, Hurricane Sandy, and the Joplin tornado, greater focus has been placed on increasing the resiliency of buildings to decrease these impacts. Investigations of building performance following tornadoes and hurricanes have shown that wind-borne debris, including loose aggregate, gravel, and stone surfacing on roofs are significant contributors to building damage and occupant injuries. Buildings may often experience little to no structural damage, but suffer failure of exterior glazing, causing catastrophic damage to building interiors and building contents that can also result in injuries and fatalities. A recent proposed code change to the International Building Code (IBC) would prohibit installation of loose aggregate surfacing on roofs of Risk Category III or IV buildings located in the most tornado-prone region of the country (covering portions of the Great Plains, Midwest, and Deep South) in order to reduce the wind-borne debris hazard, particularly to glazed openings.

Existing building codes already have provisions prohibiting the use of roof aggregate to reduce wind-borne debris hazards in hurricane-prone regions (IBC 2015, Section 1504.8), and expansion of similar provisions in the tornado-prone region are those currently being considered. However, the economic impacts of these proposed code changes to prohibit the use of roof aggregate in tornado-prone regions are not currently well understood. Needed is an assessment of the impacted building stock and the magnitude of associated costs.
\end{abstract}

The purpose of this study is to analyze the potential economic impacts from adoption of this proposed change to the IBC by identifying the fraction of roof construction that could be impacted from the restriction on aggregate surfaced roofs, characterizing alternatives to aggregate-surfaced roofing systems, and estimating the costs associated with these alternative roofing systems. The results are presented using both a national and regional perspective, including a comparison of the impacts from the restrictions on aggregate in the hurricane-prone regions.

The results demonstrate that the code change would potentially impact less than $0.1 \%$ of all roof construction in the U.S., and less than $3.0 \%$ of all non-low rise residential roof construction in the tornado-prone region. This includes roofs of newly constructed buildings and reroofing projects. The previously adopted code change that similarly prohibited aggregate-surfaced roofs in the hurricane-prone region impacted more than four times as much roof construction.

It is found that few roof construction projects will be negatively impacted from a construction cost perspective by the proposed restriction on aggregate in the 
tornado-prone region $(<0.2 \%)$ because cost-effective alternatives are available for most assemblies. Common types of aggregate-surfaced roofing that would be prohibited under the proposed code change can be more expensive than similar alternatives. For example, built-up roofs with aggregate surfacing are found to cost more than the alternative system that replaces the aggregate with a cap sheet. For single-ply roof systems over a steel roof deck, aggregate ballasted EPDM is also found to be more expensive than mechanically attached EPDM. Only in the case of the single-ply systems over a concrete roof deck are aggregate ballasted EPDM systems found to be less expensive than the alternative EPDM systems. These results hold for all 33 cities studied within the tornado-prone region.

\section{Keywords}

Building economics; roofing systems; aggregate surfacing; economic analysis; commercial buildings; building codes; building standards 


\section{Preface}

This study was jointly conducted by the Applied Economics Office (AEO) and the Structures Group of the Materials and Structural Systems Division in the Engineering Laboratory (EL) at the National Institute of Standards and Technology (NIST). The study is to support NIST's overall effort to implement recommendations NIST made as a result of the National Construction Safety Team Act investigation of the May 22, 2011 Joplin tornado (http://nvlpubs.nist.gov/nistpubs/NCSTAR/NIST.NCSTAR.3.pdf) and designed to identify the potential impacts on the commercial building sector from restricting aggregated surfaced roofing systems in areas of the United States with high tornado risk. The intended audience is researchers, standards and codes development organizations, policy makers in the commercial building sector, and others interested in building resiliency.

\section{Disclaimers}

The policy of the National Institute of Standards and Technology is to use metric units in all of its published materials. Because this report is intended for the U.S. construction industry that uses U.S. customary units, it is more practical and less confusing to include U.S. customary units as well as metric units. Measurement values in this report are therefore stated in metric units first, followed by the corresponding values in U.S. customary units within parentheses. 


\section{Acknowledgements}

The authors wish to thank all those who contributed ideas and suggestions for this report. They include Dr. Jennifer Helgeson of EL's Applied Economics Office, Mr. Matthew Boyd of EL's Energy and Environment Division, and Dr. Nicos S. Martys of EL's Materials and Structural Systems Division. A special thanks to Ms. Shannon Craig for collecting the RS Means building cost data.

\section{Author Information}

David Butry

Chief, Applied Economics Office (AEO)

National Institute of Standards and Technology

Engineering Laboratory

100 Bureau Drive, Mailstop 8603

Gaithersburg, MD 20899-8603

Tel.: 301-975-6136

Email: david.butry@nist.gov

Joshua D. Kneifel

Economist

National Institute of Standards and Technology

Engineering Laboratory

100 Bureau Drive, Mailstop 8603

Gaithersburg, MD 20899-8603

Tel.: 301-975-6857

Email: joshua.kneifel@nist.gov

Marc Levitan

Acting Director, National Windstorm Impact Reduction Program (NWIRP)

National Institute of Standards and Technology

Engineering Laboratory

100 Bureau Drive, Mailstop 8611

Gaithersburg, MD 20899-8611

Tel.: 301-975-5340

Email: marc.levitan@nist.gov 


\section{Long Phan}

Leader, Structures Group of the Materials and Structural Systems Division (MSSD)

National Institute of Standards and Technology

Engineering Laboratory

100 Bureau Drive, Mailstop 8611

Gaithersburg, MD 20899-8611

Tel.: 301-975-6077

Email: long.phan@nist.gov

Thomas Lee Smith, AIA, RRC, F.SEI

TLSmith Consulting Inc.

16681 Boswell Road

Rockton, IL 61072

Tel.: 815-629-2455

Email: tlsmith@hughes.net

Douglas Thomas

Economist

National Institute of Standards and Technology

Engineering Laboratory

100 Bureau Drive, Mailstop 8603

Gaithersburg, MD 20899-8603

Tel.: 301-975-4918

Email: douglas.thomas@nist.gov 


\section{Table of Contents}

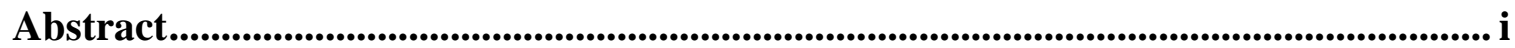

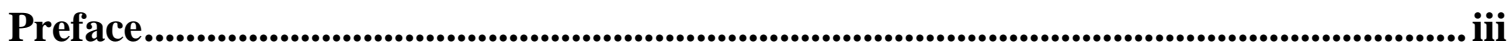

Acknowledgements ............................................................................................................................. v

Author Information ......................................................................................................................... v

List of Figures.................................................................................................................... ix

List of Tables ................................................................................................................................... ix

List of Acronyms ........................................................................................................................ xi

1 Introduction................................................................................................................. 1

1.1 Background ................................................................................................. 1

1.2 Impacts from Wind-Related Weather Events....................................................... 1

1.3 Defining Tornado-Prone Region ................................................................. 2

1.4 Applicable Risk Category of Structures.......................................................... 4

1.5 Damages from Roof Aggregate...................................................................... 5

1.62006 IBC Change related to Roof Aggregate ..................................................... 6

1.7 Current IBC Proposal for Tornado-Prone Region Related to Roof Aggregate.. 10

1.8 Purpose and Approach .................................................................................. 12

2 Estimating Potentially Impacted Roof Construction .............................................. 13

2.1 Hazus Building Stock Data ............................................................................... 13

2.2 Building Stock in Tornado-Prone Region ......................................................... 14

2.3 Comparison to the Hurricane-Prone Region ..................................................... 22

3 Costs of Alternative Roofing Systems ....................................................................... 29

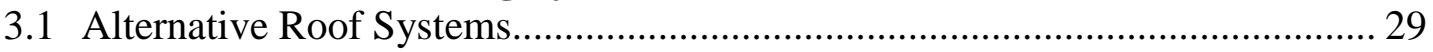

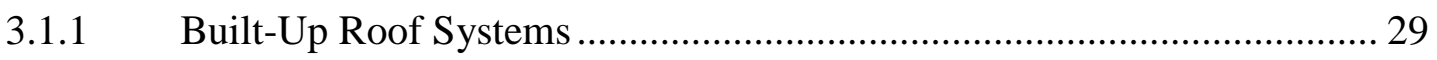

3.1.2 Single-Ply Membrane Roof Systems ....................................................... 30

3.2 Roofing Cost Data, Comparisons, and Implications ........................................... 32

3.3 Examples: 5-Story Hospital and 2-Story High School....................................... 35

4 Summary.......................................................................................................................... 37

4.1 Potential Impacts of Code Change ………………............................................. 37

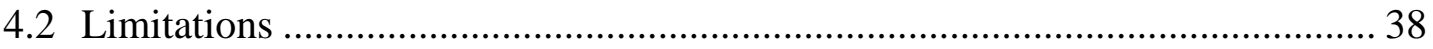

$5 \quad$ References.................................................................................................................... 39 


\section{List of Figures}

Figure 1-1 EF3 and Greater Intensity Tornado Paths (1950 to 2013) .............................. 3

Figure 1-2 Map Showing Proposed Tornado Prone Region ............................................ 4 Figure 1-3 Window (left) and Interior (right) Damage to Hospital Following the Joplin, MO Tornado. 6

Figure 1-4 Ultimate Design Wind Speeds for Risk Category II Buildings and Other

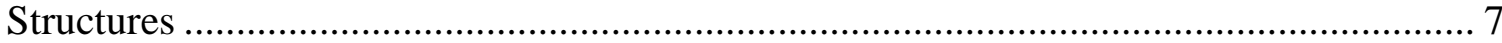

Figure 1-5 Map Showing Wind Speeds Equivalent to the Nominal Stress Design Wind Speeds Referenced in Table 1-3 10

Figure 2-1 Counties Within the Tornado-Prone Region ................................................. 14

Figure 2-2 Estimated Percentage of Risk Category III and IV Buildings, by County ..... 17

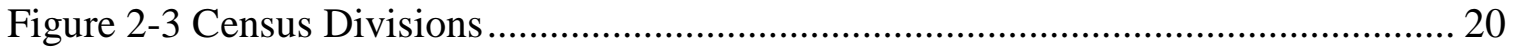

Figure 2-4 Map of Existing Hurricane-Prone and Proposed Tornado-Prone Regions ..... 23 Figure 2-5 Building Stock Counts by County with Hurricane and Tornado-Prone Regions

Figure 3-1 Example Built-Up Roof Asphalt with Aggregate (left) and Cap Sheet (right)30 Figure 3-2 Example Single-Ply Roof with Aggregate Ballast (left), Fully Adhered (center), and Mechanically Attached (right) ............................................................... 30

Figure 3-3 Representations of 5-Story Hospital: DOE (left) and RS Means (right) ........ 36

Figure 3-4 Representations of 2-Story High School: DOE (left) and RS Means (right).. 36

\section{List of Tables}

Table 1-1 U.S. Weather-Related Fatalities, Injuries, and Property Damage in 2015 ........ 2

Table 1-2 Structure Risk Categories ......................................................................... 5

Table 1-3 Maximum Allowable Mean Roof Height Permitted for Buildings with Aggregate on the Roof in Areas Outside a Hurricane-Prone Region ............................... 8

Table 1-4 States Impacted by Proposed Code Change related to Roof Aggregate ......... 12

Table 2-1 Hazus Occupancy Types and Assignment of Risk Categories........................ 16

Table 2-2 Existing Building Stock by Hazus Occupancy Type - Tornado-Prone Region

Table 2-3 Percentages of Low-Slope Roofing Projects by Roof System Type by Census

Division in the Tornado-Prone Region ...................................................................... 20

Table 2-4 Upper Bound Estimate of Percentage of Roof Construction Potentially Impacted by Proposed Code Change ............................................................................... 21

Table 2-5 Existing Building Stock by Occupancy - Tornado- vs Hurricane-Prone Region

Table 2-6 Percentages of Low-Slope Roofing Projects by Roof System Type by Census

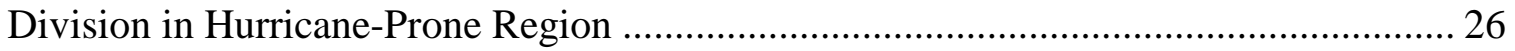

Table 3-1 Roofing Assembly Alternatives ................................................................ 29

Table 3-2 Roofing Systems and Roof Components in RS Means Databases................. 31

Table 3-3 Roofing System Cost Data - National Average ............................................ 32

Table 3-4 Assembly Cost by Location in Tornado-Prone Region................................... 34

Table 3-5 Example: Roofing System Costs of 5-Story Hospital - National Average..... 35 


\section{List of Acronyms}
AEO Applied Economics Office
BCAC Building Code Action Committee
BUR Built-Up Roof
DOE Department of Energy
EL Engineering Laboratory
EPDM ethylene propylene diene monomer
ERA EPDM Roofing Association
FEMA Federal Emergency Management Agency
IBC International Building Code
ICC International Code Council
MSSD Materials and Structural Systems Division
NIST National Institute of Standards and Technology
NRCA National Roofing Contractors Association
NWIRP National Windstorm Impact Reduction Program
PVC polyvinyl chloride
SEAKM Structural Engineers Association of Kansas and Missouri
SFCE Square Foot Cost Estimator
TPO Thermoplastic polyolefin 


\section{Introduction}

\subsection{Background}

Due to the significant life-safety and economic loss resulting from extreme, "low probability, high consequence” weather events such as Hurricane Katrina, Hurricane Sandy, and the Joplin tornado, greater focus has been placed on increasing the resiliency of buildings to decrease these impacts. Investigations of building performance following tornadoes and hurricanes have shown that wind-borne debris, including loose aggregate, gravel and stone surfacing on roofs are significant contributors to building damage and occupant injuries. Buildings often experience little to no structural damage, but suffer failure of exterior glazing, causing catastrophic damage to building interiors and building contents that can also result in injuries and fatalities. A recent proposed code change to the International Building Code (IBC) would prohibit aggregate surfacing on roofs of Risk Category III or IV buildings located in the most severe portion of the tornado-prone region of the country in order to reduce the wind-borne debris hazard, particularly to glazed openings.

Existing building codes already have provisions prohibiting the use of these roof aggregate to reduce wind-borne debris hazards in hurricane-prone regions (IBC 2015, Section 1504.8), and expansion of similar provisions in the tornado-prone region are currently being considered. However, the economic impacts of these proposed code changes to prohibit the use of roof aggregate in tornado-prone regions are not currently well understood. Needed is an assessment of the impacted building stock and the magnitude of associated costs.

\subsection{Impacts from Wind-Related Weather Events}

Wind-related weather events are some of the most impactful when it comes to fatalities and injuries as well as property damage. Table 1-1 shows that the combination of tornadoes, hurricanes, thunderstorm wind, and other high winds claimed 115 lives and caused 1195 injuries and $\$ 706$ million in property damage in 2015 (NOAA 2016a). Of all wind-related weather events, tornadoes result in some of the greatest impacts across all three categories of damages. Property damage from tornadoes totaled \$317 million in 2015, 7.5 times that of hurricanes. Of the 2143 weather-related injuries and illnesses in 2015, tornadoes were responsible for 924, or $43 \%$ of those reported in the U.S., which is 5.8 times greater than those caused by hurricanes. Tornadoes have led to 110 fatalities annually, on average, over the last 10 years while other windstorms and hurricanes have led to 56 and 43 fatalities annually, respectively (NOAA 2016b). Since the beginning of official tornado record keeping (1950) through 2011, U.S. tornadoes have caused about 5600 fatalities

(www.nws.noaa.gov/om/hazstats/resources/weather_fatalities.pdf). This number well exceeds the toll for U.S. hurricanes and earthquakes over the same period, 3102 (NOAA (www.noaanews.noaa.gov/2011_tornado_information.html) and 459 (http://earthquake.usgs.gov/earthquakes/states/us_deaths.php), respectively. The May 22, 2011 
Joplin, MO, tornado in particular was ranked the deadliest and costliest single tornado on record. It caused 161 fatalities, more than 1000 injuries, and damaged nearly 8000 structures and incurred close to $\$ 3$ billion in insured losses (NIST 2014).

Table 1-1 U.S. Weather-Related Fatalities, Injuries, and Property Damage in 2015

\begin{tabular}{|l|r|l|r|r|r|}
\hline \multicolumn{1}{|c|}{$\begin{array}{c}\text { Impact } \\
\text { Categories }\end{array}$} & Tornado & $\begin{array}{l}\text { Tropical Storm } \\
\text { / Hurricane }\end{array}$ & $\begin{array}{l}\text { Thunderstorm } \\
\text { Wind }\end{array}$ & $\begin{array}{l}\text { High } \\
\text { Wind }\end{array}$ & $\begin{array}{l}\text { U.S. } \\
\text { Total }\end{array}$ \\
\hline Fatalities & 36 & 14 & 41 & 24 & 522 \\
\hline Injuries & 924 & 50 & 159 & 62 & 2143 \\
\hline Property Damage (million \$) & 316.8 & 41.5 & 252.0 & 65.5 & 4202.0 \\
\hline Source: NOAA 2016a
\end{tabular}

\subsection{Defining Tornado-Prone Region}

Tornadoes can occur in all 50 states, but the strongest and most frequent tornadoes occur in the Great Plains, Midwest, and Deep South. Tornadoes are rated in intensity using the Enhanced Fujita (EF) Scale, which ranges from 1 to 5 with 5 being the strongest, Figure 1-1 maps the EF3 (green), EF4 (yellow), and EF5 (red) tornadoes reported between 1950 and 2013. For additional information on the EF scale, see NOAA 2016e. 


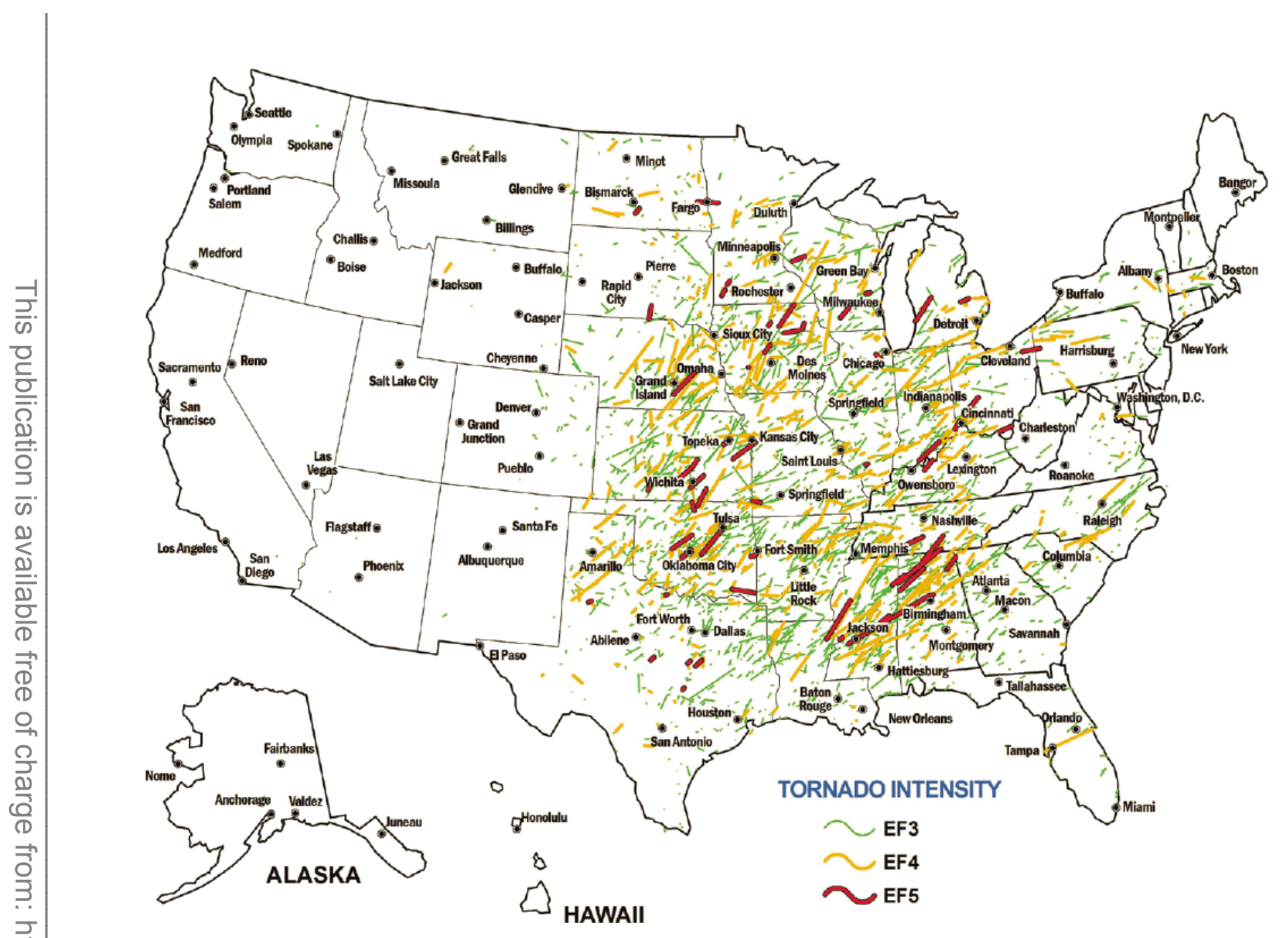

Figure 1-1 EF3 and Greater Intensity Tornado Paths (1950 to 2013) ${ }^{1}$

Based on analysis of tornado frequency and intensity data, the map shown in Figure 1-2 was created to identify areas in the U.S. that are at risk of winds from tornadoes, for use in design of storm shelters (ICC 2014c). The proposed IBC code change designates the tornado prone region to be an area of the country within the $250 \mathrm{mph}$ wind speed zone, as shown in dark gray in Figure 1-2.

${ }^{1}$ Source: FEMA (2015) 


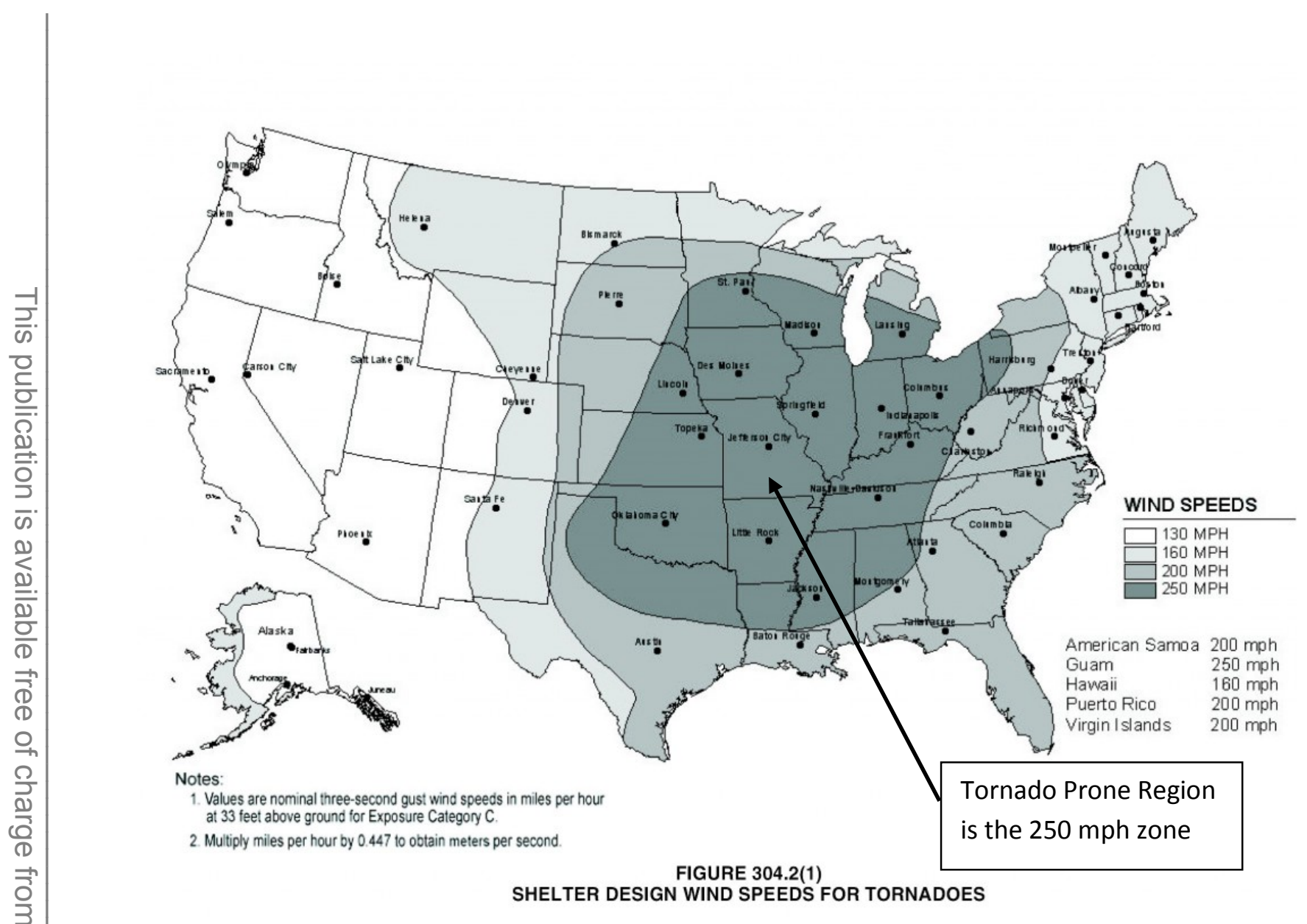

Figure 1-2 Map Showing Proposed Tornado Prone Region ${ }^{2}$

\subsection{Applicable Risk Category of Structures}

For structural design purposes, IBC (Table 1604.5) classifies buildings into four risk categories according to their occupancy type. The building types associated with each of the four Building Risk Categories can be seen in Table 1-2 from IBC 2015. This study focuses on Risk Category III and IV buildings, which are the subject of the proposed code change.

${ }^{2}$ ICC (2014c). Enhancements by NIST. 
Table 1-2 Structure Risk Categories ${ }^{3}$

\begin{tabular}{|c|c|}
\hline $\begin{array}{c}\text { Risk } \\
\text { Category }\end{array}$ & Nature of Occupancy \\
\hline I & $\begin{array}{l}\text { Buildings and other structures that represent a low hazard to human life in the event of failure, } \\
\text { including but not limited to: } \\
\text { - Agricultural facilities, certain temporary facilities, minor storage facilities, and screen enclosures. }\end{array}$ \\
\hline II & Buildings and other structures except those listed in Risk Categories I, III and IV. \\
\hline III & $\begin{array}{l}\text { Buildings and other structures that represent a substantial hazard to human life in the event of } \\
\text { failure, including but not limited to: } \\
\text { - } \quad \text { Buildings and other structures whose primary occupancy is public assembly with an occupant load } \\
\text { greater than } 300 \\
\text { - Buildings and other structures containing elementary school, secondary school or daycare facilities } \\
\text { with an occupant load greater than } 250 \text {. } \\
\text { - } \quad \text { Buildings and other structures containing adult education facilities, such as colleges and } \\
\text { universities, with an occupant load greater than } 500 \text {. } \\
\text { - Group I-2 occupancies with an occupant load of } 50 \text { or more resident patients but not having } \\
\text { - } \quad \text { Gurgery or emergency treatment facilities. } \\
\text { - } \quad \text { Any other occupancies. } \\
\text { - Power-generating stations, water treatment facilities for potable water, waste water treatment } \\
\text { - } \quad \text { Bacilities and other public utility facilities not included in Risk Category IV. } \\
\text { toxic or explosive substances to be dangerous to the public if released. }\end{array}$ \\
\hline IV & 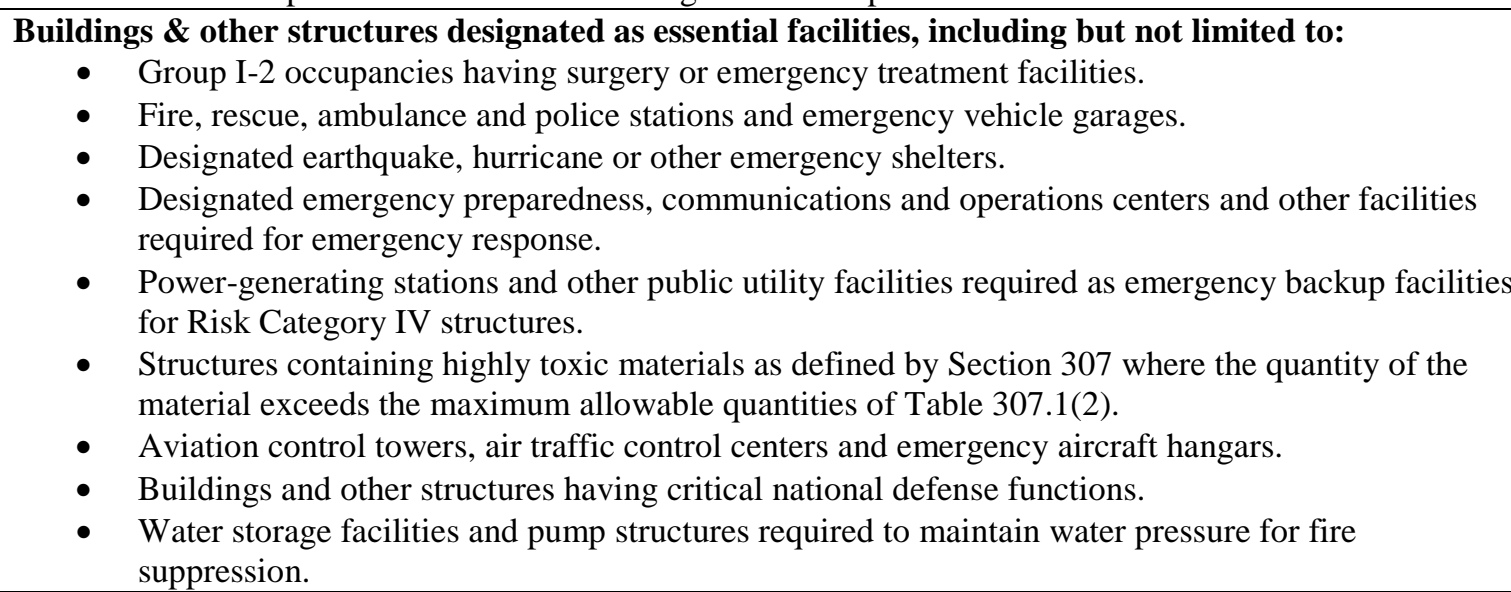 \\
\hline
\end{tabular}

\subsection{Damages from Roof Aggregate}

There are many types of debris generated during high wind events, all of which create risk of property damage, fatalities, and injuries. Much of that debris would be difficult, or impossible, to mitigate because of the randomness of its location. However, one particular type of debris that could be directly mitigated with code changes is aggregate from roofs.

\footnotetext{
${ }^{3}$ ICC (2014b) Table 1604.5 Risk Category of Buildings and Other Structures
} 
Investigations of building performance following tornadoes and hurricanes have shown that loose aggregate, gravel and stone used as surfacing on roofs are significant contributors to building damage and injuries. These buildings often experience little to no damage to the structural systems, but nevertheless suffer catastrophic damage to their envelopes and exterior glazing, leading to significant damage to building interiors and contents that can also result in injuries and fatalities. In particular, buildings in Risk Category III and IV (see Table 1-2), such as schools and hospitals, have often experienced significant glazing damage due to aggregate "blow-off" from their own roofs, and/or roofs of nearby buildings during tornadoes (e.g., NIST 2014, FEMA 2007, FEMA 2010, and FEMA 2012) and hurricanes (e.g., NIST 2006 and FEMA 2005). For example, Figure 1-3 shows the glazing failures (left) and interior damage (right) in the East Tower at St John's Regional Medical Center following the Joplin tornado (NIST 2014). Note the extensive amount of roof aggregate inside the building. The Federal Emergency Management Agency (FEMA) has also documented instances where people have been injured after being struck directly by roof aggregate in tornadoes in Illinois (FEMA 2010) and Texas (FEMA 2007). These studies have led to a number of adopted or proposed changes to building codes to prevent these damages in the future.
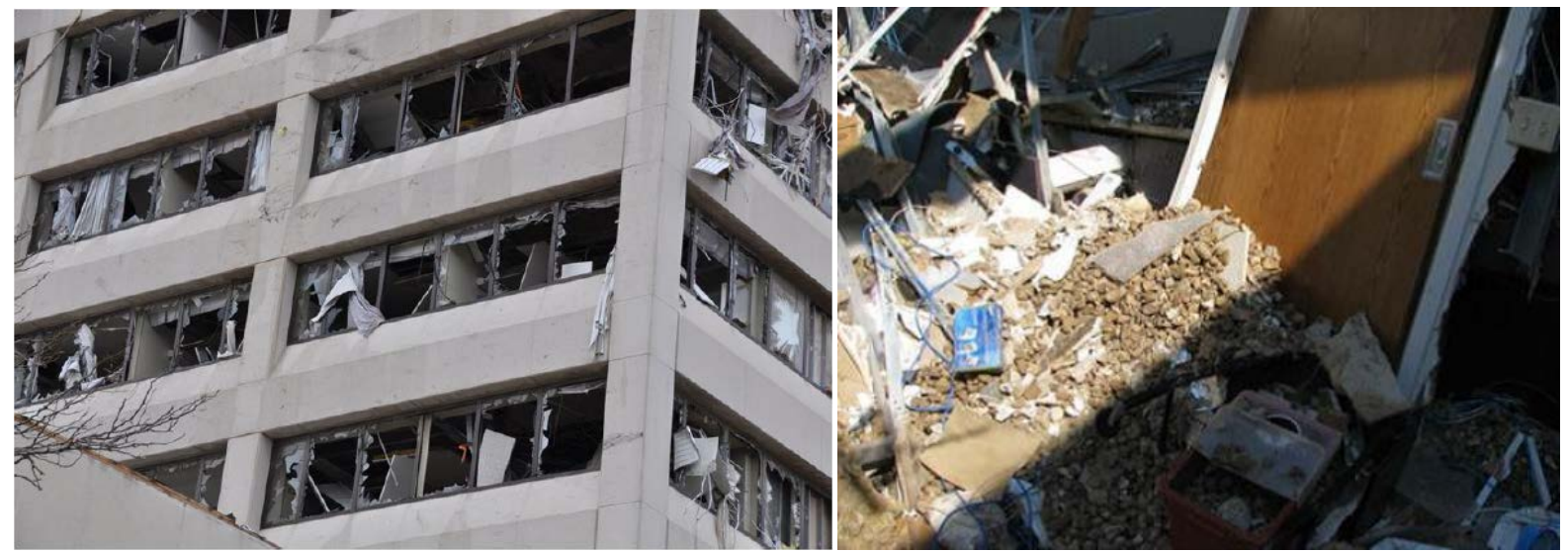

Figure 1-3 Window (left) and Interior (right ${ }^{4}$ ) Damage to Hospital Following the Joplin, MO Tornado

\subsection{IBC Change related to Roof Aggregate}

The 2006 edition of the International Building Code (IBC) prohibited the use of aggregate roof surfacing in hurricane-prone regions while allowing its use in other regions based on mean roof height and exposure category. Such restrictions remain in the 2015 IBC with the following language:

IBC 1504.8 Aggregate. Aggregate used as surfacing for roof coverings and aggregate, gravel or stone used as ballast shall not be used on the roof of a

\footnotetext{
${ }^{4}$ Copyright 2011 Malcolm Carter. Used with Permission.
} 
building located in a hurricane-prone region as defined in Section 202, or on any other building with a mean roof height exceeding that permitted by Table 1504.8 based on the exposure category and basic wind speed at the site.

IBC defines the hurricane-prone region (Section 202) as

Areas vulnerable to hurricanes defined as:

1. The U.S. Atlantic Ocean and Gulf of Mexico coasts where the ultimate design wind speed, $V_{u l t}$, for Risk Category buildings is greater than 115 $m p h(51.4 \mathrm{~m} / \mathrm{s})$;

2. Hawaii, Puerto Rico, Guam, Virgin Islands and American Samoa.

using wind speeds shown in Figure 1-4.

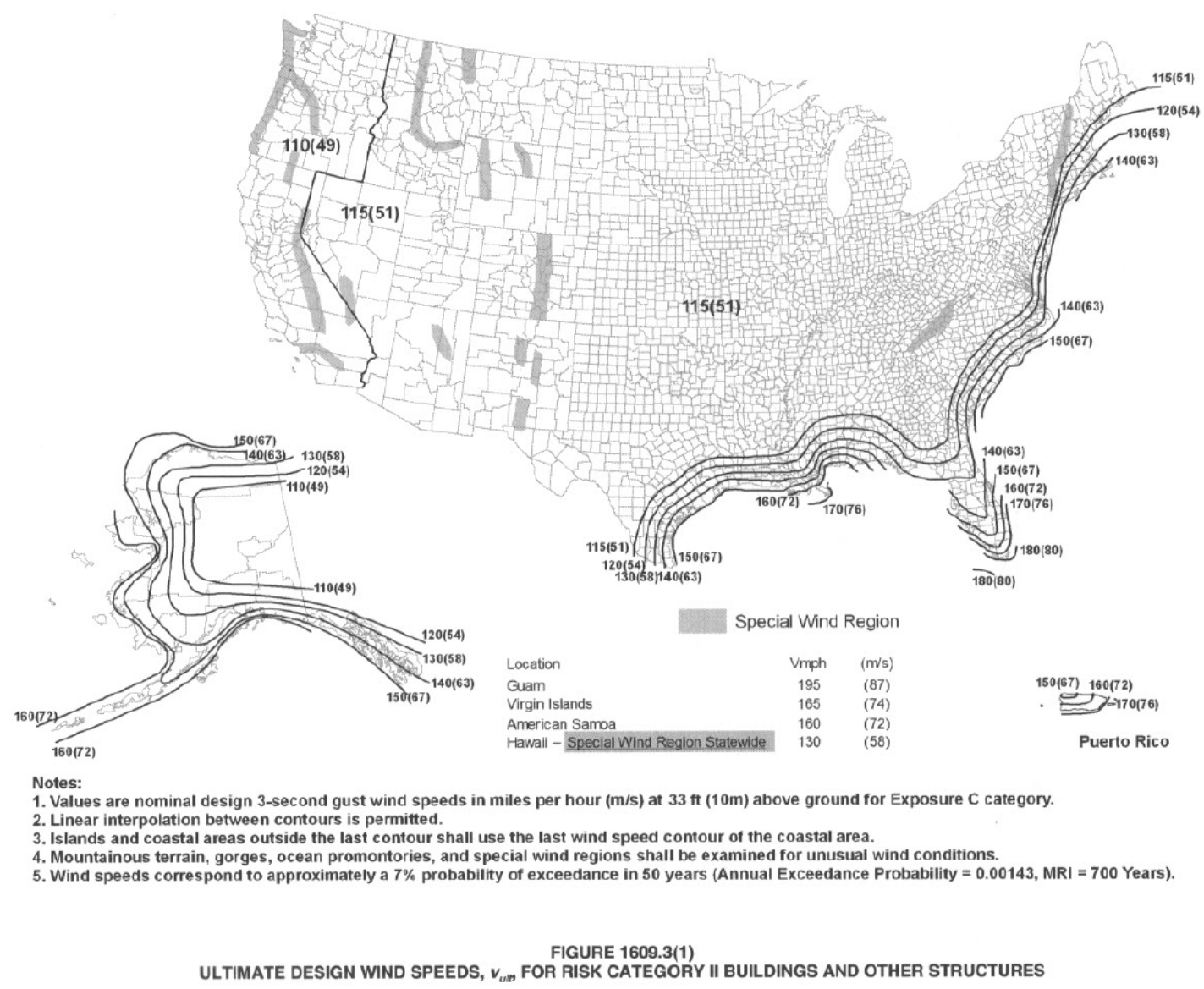

Figure 1-4 Ultimate Design Wind Speeds for Risk Category II Buildings and Other Structures $^{5}$

${ }^{5}$ ICC (2014b) Figure 1609.3(1) 
The restrictions on aggregate roof surfacing outside of the hurricane prone region are shown in Table 1-3, adapted from IBC Table 1504.8 (ICC 2014b). The nominal stress design wind speed referred to in this table is equal to the ultimate design wind speed shown in Figure 1-4 times the square root of 0.6, which is equivalent to the basic wind speed mapped in the 2012 International Residential Code (ICC 2011), reproduced in Figure 1-5. Examination of this map and Figure 1-2 shows that a $145 \mathrm{~km} / \mathrm{hr}(90 \mathrm{mph})$ wind speed applies to most of the proposed tornado-prone region (with the exception of the southeastern-most part of the tornado-prone region where wind speeds increase due to proximity to the hurricane prone region along the Gulf Coast - see also Figure 2-4).

\section{Table 1-3 Maximum Allowable Mean Roof Height Permitted for Buildings with Aggregate on the Roof in Areas Outside a Hurricane-Prone Region}

\begin{tabular}{|c|c|c|c|}
\hline \multirow{3}{*}{$\begin{array}{l}\text { Nominal Stress } \\
\text { Design Wind } \\
\text { Speed*** (mph) }\end{array}$} & \multirow{2}{*}{\multicolumn{3}{|c|}{$\frac{\text { Maximum Mean Roof Height* }(\mathrm{ft})}{\text { Exposure Category }}$}} \\
\hline & & & \\
\hline & B & C & $\mathrm{D}$ \\
\hline 85 & 170 & 60 & 30 \\
\hline 90 & 110 & 35 & 15 \\
\hline 95 & 75 & 20 & NP \\
\hline 100 & 55 & 15 & NP \\
\hline 105 & 40 & NP & NP \\
\hline 110 & 30 & NP & NP \\
\hline 115 & 20 & NP & NP \\
\hline 120 & 15 & NP & NP \\
\hline$>120$ & NP & NP & NP \\
\hline \multicolumn{4}{|c|}{$\begin{array}{l}\text { *Mean roof height as defined in ACSE } 7 . \\
* * \text { NP }=\text { Gravel and stone not permitted for any roof } \\
\text { height. } \\
* * * \text { The nominal stress design wind speed is equal to } \\
\text { the ultimate design wind speed as shown in Figure } \\
1-4 \text { times } \sqrt{ } 0.6 \text {. } \\
\text { Conversions: } 1 \mathrm{mph}=0.44704 \mathrm{~m} / \mathrm{s} ; 1 \mathrm{ft}=0.3048 \mathrm{~m} \\
\text { Bold shows roof heights above which aggregate } \\
\text { surfaced roofs are already prohibited in most of the } \\
\text { tornado-prone region }\end{array}$} \\
\hline
\end{tabular}

Roof aggregate is not allowed for buildings above a given height for all three exposure categories at a nominal stress design wind speed of $145 \mathrm{~km} / \mathrm{hr}(90 \mathrm{mph})$. This requirement is due to the increase of wind speed with height, which varies in winds flowing over different exposures. As shown in Figure 1-5, almost the entire contiguous U.S., excluding the states on the West Coast (California, Oregon, and Washington) and seaward portions of the states along the Gulf of Mexico and East Coast, is encompassed in the $145 \mathrm{~km} / \mathrm{hr}(90 \mathrm{mph})$ region. Therefore, roof aggregate is currently not allowed for buildings taller than $33.5 \mathrm{~m}(110 \mathrm{ft}), 10.7 \mathrm{~m}(35 \mathrm{ft})$,

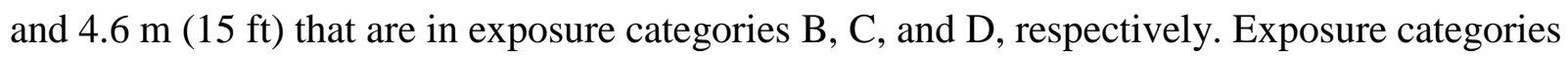
are defined in IBC Section 1609.4.3 (ICC 2014b) and summarized below, which has specific application to IBC Table 1-3: 
- Exposure B = Urban and suburban areas, wooded areas, areas with many closely spaced obstructions, extending for at least $457 \mathrm{~m}(1500 \mathrm{ft})$ in all directions for buildings with mean

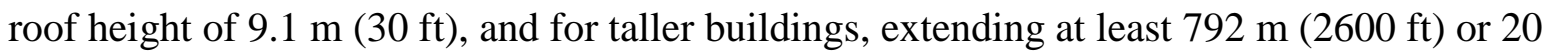
times the height of the building in all directions.

- Exposure $\mathrm{C}=$ Open terrain with scattered obstructions. Includes airports and areas that are generally flat open country.

- Exposure D = Flat, unobstructed areas and water surfaces. This category includes smooth mud flats, salt flats, and unbroken ice that extend $1524 \mathrm{~m}$ (5000 ft) or 20 times the building height in any direction.

Buildings located in urban, suburban, or wooded areas are subject to the Exposure B restriction in Table 1-3, which does not allow roof aggregate for buildings taller than $33.5 \mathrm{~m}$ (110 ft). Therefore, buildings of about 10 stories or less (assuming $3.4 \mathrm{~m}$ (11 ft) per story) in Exposure B currently have no restriction on roof aggregate throughout most of the tornado-prone region. However, for buildings located in Exposure C, which is flat open terrain that is more common across much of the western part of the tornado-prone region, roof aggregate is already restricted

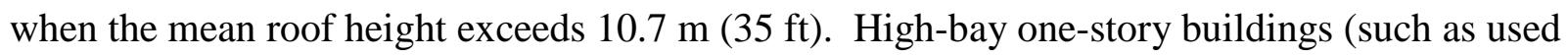
in some manufacturing and warehousing applications) commonly exceed this $35 \mathrm{ft}$ threshold, so are already subject to roof aggregate restrictions, as are some three-story and all four-story and taller buildings located in Exposure C. All buildings with mean roof height exceeding $4.6 \mathrm{~m}$ (15 ft) in Exposure D (less common) are subject to the existing roof aggregate restrictions, which would exclude only some single story buildings. 


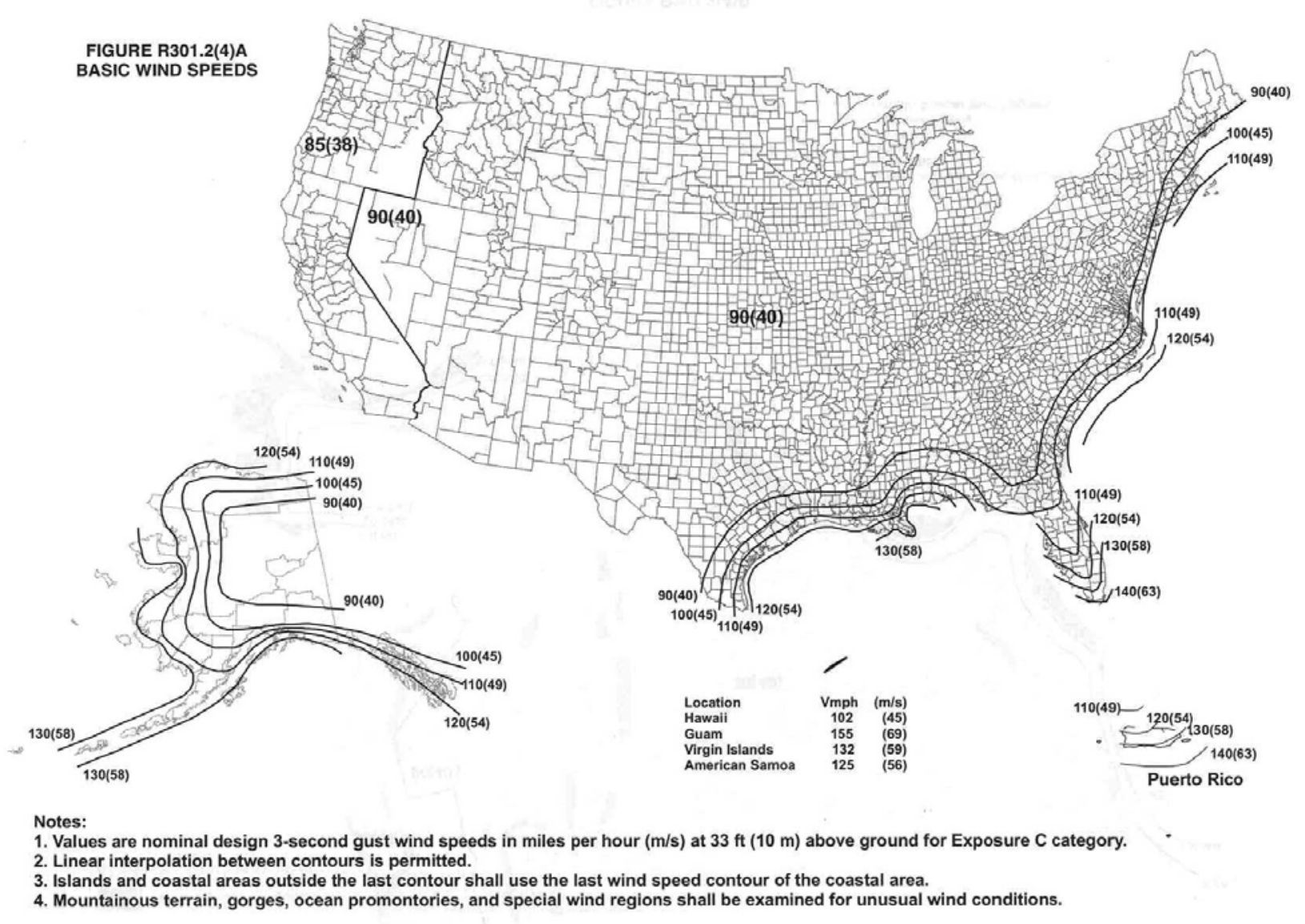

Figure 1-5 Map Showing Wind Speeds Equivalent to the Nominal Stress Design Wind Speeds Referenced in Table 1-3

\subsection{Current IBC Proposal for Tornado-Prone Region Related to Roof Aggregate}

Similar to the change to the building code adopted in the IBC to address damage from roof aggregate in hurricane-prone regions and for buildings taller than $33.5 \mathrm{~m}$ (110 ft) located elsewhere (excluding West Coast states), a recently proposed change would also restrict use of aggregate for Risk Category III and IV buildings in the tornado-prone region (defined in Section 1-3). The specific language of this code change proposal, jointly developed by the ICC's Building Code Action Committee (BCAC) and the National Institute of Standards and Technology (NIST), in consultation with experts from the roofing industry, is as follows: (ICC 2016a, proposal S22-16)

1504.9 Surfacing and ballast materials in tornado-prone regions. Aggregate shall not be used as surfacing for roof coverings and aggregate, gravel or stone shall not be used as ballast on the roof of a Risk Category III or IV building 
located in areas where the wind speed is $250 \mathrm{MPH}$ in accordance with Figure 304.2(1) of ICC 500.

The proposed language was modified slightly in a Public Comment as shown below (ICC 2016b), which was jointly developed by the BCAC and NIST in response to concerns raised at the Committee Action Hearings held in Louisville in April, 2016

\subsection{Surfacing and ballast materials in tornado-prone regions. Aggregate shall not be used as surfacing for roof coverings and aggregate, gravel or stone shall not be used as ballast on the roof of a Risk Category III or IV building located in the region having the greatest wind speed in Figure 304.2(1) of ICC 500.}

The proposed code change is consistent with findings and recommendations from the NIST technical investigation of the 2011 tornado in Joplin Missouri (NIST 2014, Finding 19, and Recommendation 10). This change proposal is also consistent with FEMA recommendations, developed from observations of building performance in tornadoes. FEMA recommends that aggregate roof surfacing not be specified for critical facilities in tornado-prone regions (FEMA 2012). The NIST and FEMA recommendations are intended to reduce the wind-borne debris hazard by reducing the potential number of "missiles" generated by a tornado, and hence reduce the potential for building damage and injury to people. Additionally, the proposed code change is consistent with recommendations made by the Structural Engineers Association of Kansas and Missouri following their investigation of the Joplin tornado (SEAKM 2012, Recommendation \#9).

The probability of aggregate "blow-off" from roofs outside of hurricane-prone regions is generally small except in the case of a tornado. Since the probability of a site-specific tornado strike is also low, the proposal is limited to Risk Category III and IV buildings. Although tornadoes generate many types of debris, an aggregate surfaced roof has a tremendous number of potential missiles. For example, an aggregate ballasted $1858 \mathrm{~m}^{2}\left(20000 \mathrm{ft}^{2}\right)$ single-ply roof would have approximately 1.6 million loose aggregates. A similarly sized built-up roof would have approximately 4.5 million to 9.0 million loose aggregates, depending on gradation (based on aggregate samples collected from a number of roofs reported by FEMA (2006). The proposed code change will eliminate these millions of potential projectiles.

As shown in Figure 1-2 and listed in Table 1-4, the proposed code change would impact Risk Categories III and IV buildings in 22 states in the central U.S., including the entirety of Arkansas, Illinois, Indiana, Iowa, Missouri, and Ohio. Significant portions of Alabama, Kentucky, Louisiana, Michigan, Minnesota, Mississippi, Nebraska, Oklahoma, Tennessee, Texas, and Wisconsin, and small portions of Georgia, Pennsylvania, New York, South Dakota, and West Virginia would also be impacted. Of the 22 states, 17 would have a significant portion of their state potentially impacted by this proposed code change. 
Table 1-4 States Impacted by Proposed Code Change related to Roof Aggregate

\begin{tabular}{|l|cccccccc|}
\hline Portion of State Land Mass & \multicolumn{8}{|c|}{ States Impacted } \\
\hline Entire State & AR & IL & IN & IA & MO & OH & \\
\hline Nearly Entire State & KY & OK & TN & & & & & \\
\hline Significant Portion of State & AL & LA & MI & MN & MS & NE & TX & WI \\
\hline Small Portion of State & GA & NY & PA & SD & WV & & & \\
\hline
\end{tabular}

\subsection{Purpose and Approach}

The purpose of this study is to analyze the potential economic impacts from adoption of this proposed change to the IBC by identifying the fraction of the building stock that could be impacted from the restriction on aggregate roofs, characterizing alternatives to aggregatesurfaced roofing systems, and estimating the costs associated with these alternative roofing systems. The number of buildings potentially impacted will be identified by combining building stock data from Hazus (FEMA 2009) by occupancy type, roofing system construction market share data from the National Roofing Contractors Association (NRCA 2015) and EPDM Roofing Association (ERA 2016), and RS Means roofing system cost data (RS Means 2016a). The results will be put into perspective from both a national and regional level, including a comparison of the impacts from the existing IBC restrictions on roof aggregate in hurricane-prone regions. 


\section{Estimating Potentially Impacted Roof Construction}

The proposed change in the IBC will only impact a small fraction of U.S. roof construction, either through re-roofing projects or for roofing of new buildings. The only buildings that are eligible to be impacted are buildings that meet four requirements: (1) located within the tornadoprone region, (2) classified as Risk Category III or IV buildings, (3) built with a low slope roof, and (4) would be constructed or re-roofed using aggregate-surfaced roofing systems if not for the new restriction. This chapter uses Hazus building stock and building occupancy type data to estimate the percentage of existing buildings meeting requirements 1 and 2, and uses NRCA and ERA roof system construction data to control for requirements 3 and 4 together (no data is explicitly available on roof slopes of the existing building stock).

There is a fifth requirement that cannot be controlled for given the available data. Under provisions that were introduced in the 2006 IBC (discussed previously), buildings in the tornado-

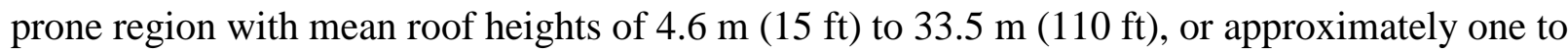
10 stories, depending on terrain exposure, are already restricted from using roof aggregate. The building stock data used in this analysis does not include building height or exposure information. Not controlling for building height and exposure will bias the final results towards overestimation of the impacts of the proposed code change, as many buildings that are already restricted from using aggregate roof surfacing will not be excluded from the pool of potentially impacted buildings. As described later, assumptions made during the analysis of each of the first four requirements also lead to an overestimation of potential impacts. Therefore, the results presented in this chapter are effectively upper bounds; the anticipated impacts of the code change are expected to be smaller, and perhaps substantially so.

The percentage of potentially impacted roof construction will be identified by combining building stock data by occupancy type from Hazus (FEMA 2009) that are likely to be Risk Category III or IV buildings with roofing system construction market share data from the National Roofing Association (NRCA 2015) and EPDM Roofing Association (ERA 2016). RS Means roofing system cost data (RS Means 2016a) will be used to estimate the cost of commonly used aggregate roofing systems, along with non-aggregate alternative systems.

\subsection{Hazus Building Stock Data}

Hazus provides a standardized methodology to assess losses from earthquakes, hurricane winds, and floods (FEMA 2014). It leverages data from the Census Bureau, among other sources, to inventory the building stock for the U.S., and provides the data at the census tract level. For this study, the census tract data is aggregated to calculate a building count by occupancy type at the county level using data in Hazus-MH MR4 Version 1.4 (FEMA 2009). 


\subsection{Building Stock in Tornado-Prone Region}

Of the 3219 counties in the Hazus database, 1456 counties are at least partially within the tornado-prone region, including 33 metropolitan areas as shown in Figure 2-1. Cities span from Dallas, TX (south) to Minneapolis, MN (north) and Amarillo, TX (west) to Cleveland, $\mathrm{OH}$ (east). The following analysis assumes the building stock for the tornado-zone region includes the building stock data for these 1456 counties. The full number of buildings is included even for counties that are only partially in the tornado-prone region, so building stock counts are overestimates, which will slightly bias the impacts reported as a percentage of the U.S. market, but should not have much effect on estimated regional impacts.

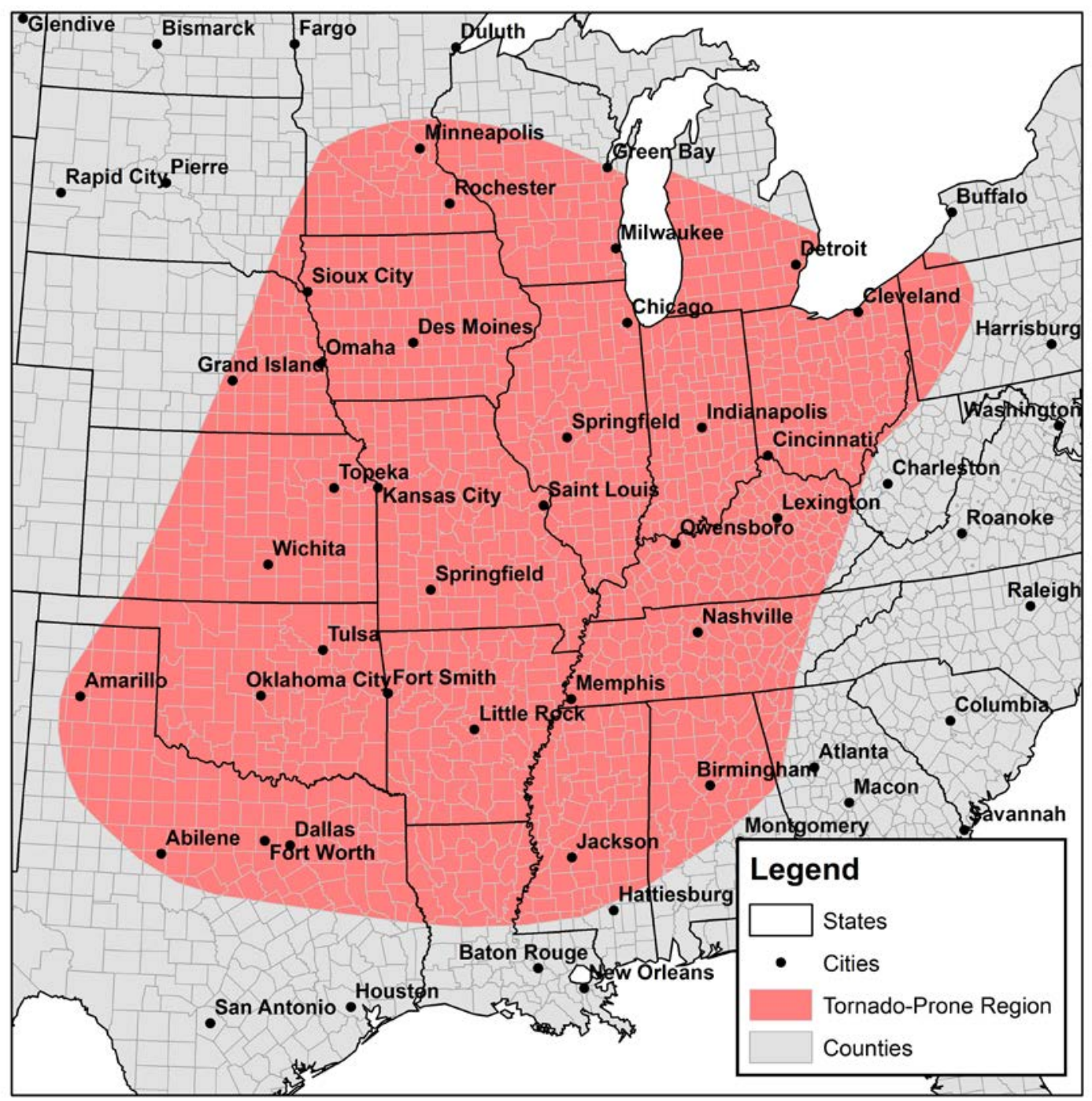

Figure 2-1 Counties Within the Tornado-Prone Region 
Buildings with Risk Category III and IV designations (defined in Table 1-2) could include public assembly buildings, schools, colleges, universities, daycare centers, hospitals, other patient care facilities, utility facilities, facilities that handle dangerous materials, emergency services, and any building with occupancy greater than 5000. Hazus occupancy types likely to be designated as Risk Category III or IV structures were mapped against the IBC requirements shown in Table 2-1, which include: institutional residential facilities, nursing homes, hospitals, medical offices, entertainment, theaters, general government services, government emergency centers, schools, and colleges.

Note that these selections are an approximation, as the occupancy categories in Hazus and the Risk Categories in the IBC are not identical, and no information is available on the occupant load of the building stock, which is a factor in the IBC table. For example, only schools with occupant loads greater than 250 and college buildings with occupant loads greater than 300 are required to be Risk Category III buildings per IBC, but since no occupant load information is available in the Hazus building stock data, all school and college buildings in the Hazus data were assumed to be Risk Category III. Similarly, minimum occupant loads for other occupancies, such as places of public assembly and medical care facilities (I-2 occupancy in Table 1-2), could not be controlled for, so all of the Hazus buildings having occupancy types of entertainment, theater, hospital, and medical office were assigned to Risk Category III/IV. Although less common than the preceding problem of over-assigning building stock to Risk Category III/IV, it would also be expected that some existing buildings which are Risk Category III/IV would not be mapped as such in Table 2-1. For example, churches and other places of religious worship with occupant loads greater than 250 would be considered places of public assembly in the IBC and assigned to Risk Category III. While low-slope, aggregate-surfaced roofs are not commonly used for churches, there are likely a modest number of religious occupancy buildings that would fit this category. Another example would include certain industrial and agricultural buildings that contain sufficient quantities of toxic or explosive substances that are dangerous to the public if released. These would be assigned Risk Category III or IV by the IBC.

The net effect of data limitations on the assignment of Risk Category to Hazus building stock data may bias the final results towards overestimation of the impacts of the proposed code change, because a larger percentage of the existing building were assigned Risk Category III/IV when they are in fact in other risk categories. 
Table 2-1 Hazus Occupancy Types and Assignment of Risk Categories

\begin{tabular}{|l|l|c|}
\hline \multicolumn{2}{|c|}{$\begin{array}{c}\text { Occupancy } \\
\text { Type }\end{array}$} & $\begin{array}{c}\text { Risk } \\
\text { Category } \\
\text { III or IV }\end{array}$ \\
\hline RES1I & Residential Single-Family & \\
\hline RES2I & Residential Manufactured Housing & \\
\hline RES3AI & Residential Duplex & \\
\hline RES3BI & Residential 3-4 Units & \\
\hline RES3CI & Residential 5-9 Units & \\
\hline RES3DI & Residential 10-19 Units & \\
\hline RES3EI & Residential 20-49 Units & \\
\hline RES3FI & Residential 50+ Units & $\mathbf{X}$ \\
\hline RES4I & Residential Temp Lodging & $\mathbf{X}$ \\
\hline RES5I & Residential Institutional & \\
\hline RES6I & Residential Nursing Home & \\
\hline COM1I & Retail Trade & \\
\hline COM2I & Wholesale Trade & \\
\hline COM3I & Personal Service & \\
\hline COM4I & Professional & \\
\hline COM5I & Banking & \\
\hline & \multicolumn{2}{|l}{} \\
\hline & & \\
\hline
\end{tabular}

\begin{tabular}{|l|l|c|}
\hline \multicolumn{2}{|c|}{$\begin{array}{c}\text { Occupancy } \\
\text { Type }\end{array}$} & $\begin{array}{c}\text { Risk } \\
\text { Category } \\
\text { III or IV }\end{array}$ \\
\hline COM6I & Hospital & $\mathbf{X}$ \\
\hline COM7I & Medical Office & X \\
\hline COM8I & Entertainment & $\mathbf{X}$ \\
\hline COM9I & Theaters & $\mathbf{X}$ \\
\hline COM10I & Parking & \\
\hline IND1I & Heavy Industrial & \\
\hline IND2I & Light Industrial & \\
\hline IND3I & Food/Drug & \\
\hline IND4I & Metals & \\
\hline IND5I & High Tech & \\
\hline IND6I & Construction & \\
\hline AGR1I & Agriculture & \\
\hline REL1I & Religious & \\
\hline GOV1I & General Services & $\mathbf{X}$ \\
\hline GOV2I & Emergency Center & $\mathbf{X}$ \\
\hline EDU1I & Schools & $\mathbf{X}$ \\
\hline EDU2I & Colleges & $\mathbf{X}$ \\
\hline & \multicolumn{2}{|l|}{} \\
\hline
\end{tabular}

Figure 2-2 shows the estimated percentage of existing Risk Category III and IV buildings in the tornado-prone region based on the definition of building stock and applicable building occupancy types from Table 2-1. The percent of Risk Category III and IV buildings varies significantly, from 0 to $5 \%$, depending on the county, with "hotspots" in and around the metropolitan areas mentioned previously. 


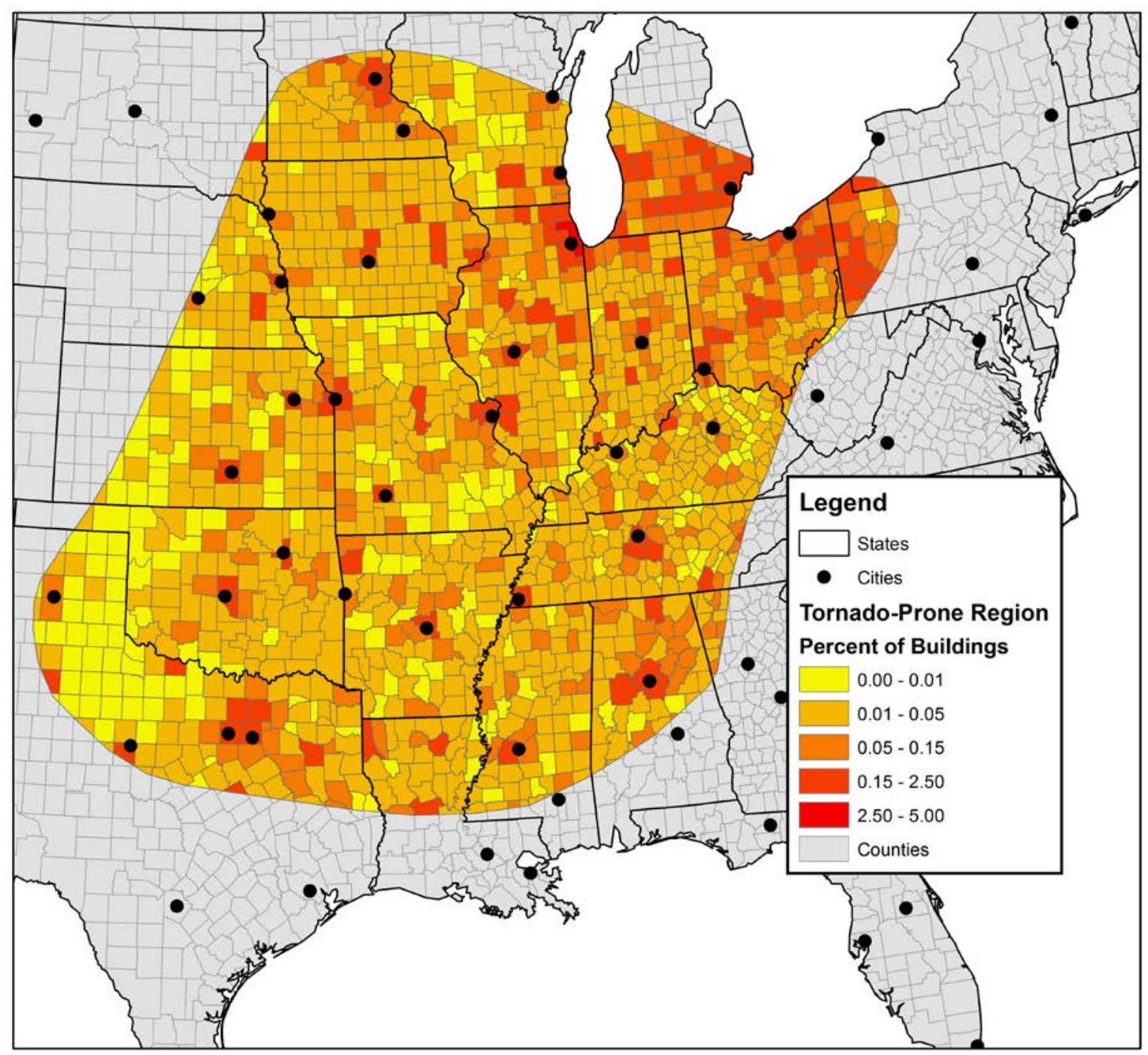

Figure 2-2 Estimated Percentage of Risk Category III and IV Buildings, by County

Aggregation of the building stock for the tornado-prone region compared to the U.S. building stock is shown in Table 2-2. The tornado-prone region accounts for $36 \%$ of the building stock, ranging from $22 \%$ to $43 \%$ depending on the occupancy type. Of the occupancy types identified as Risk Category III and IV buildings, the tornado-prone region accounts for $29 \%$ to $37 \%$ depending on the occupancy type, with an overall average of $33 \%$. The Risk Category III and IV buildings are estimated to comprise $1.5 \%$ of the building stock in the tornado-prone region.

Low-rise residential buildings, including single-family homes, manufactured housing, duplexes, and small apartment buildings, typically have non-low-slope roofs and should not be considered in the same roofing market. Excluding all residential buildings with fewer than 50 units, the total U.S. building stock is reduced from 110.3 million to 10.1 million (91 \% reduction) with similar effects in the tornado-prone region. The building stock occupancy types for Risk Category III 
and IV buildings in the tornado-prone region becomes $6.0 \%$ of the entire U.S. building stock (excluding residential with less than 50 units) and $17.6 \%$ of the building stock in the tornadoprone region (excluding residential with less than 50 units). For the remainder of this study, residential buildings with fewer than 50 units will be considered synonymous with "low-rise residential buildings.”

Table 2-2 Existing Building Stock by Hazus Occupancy Type - Tornado-Prone Region

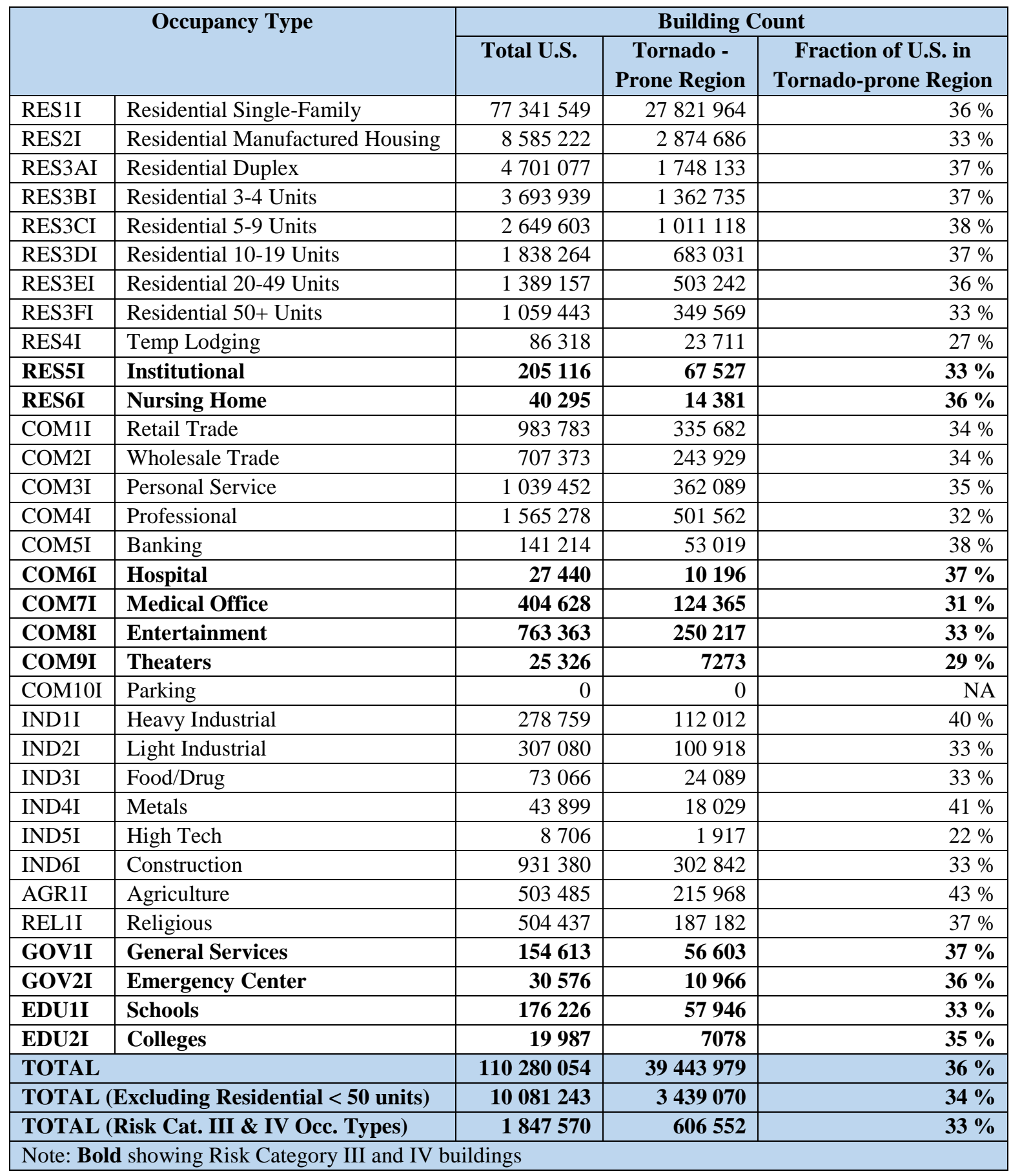


The above building stock estimates include all buildings in each occupancy type. However, not all buildings have low-slope roofs, and not all buildings with low-slope roofs are surfaced with roof aggregate. The National Roofing Contractors Association Annual Market Survey (NRCA 2015) estimates that built-up roofs (BURs) (hot-applied asphalt or coal tar, and cold process) accounted for $5.2 \%$ of all new low-slope roof construction and $9.9 \%$ of all re-roofing of lowslope roof projects nationwide in 2014. Ethylene propylene diene monomer (EPDM), which may include a layer of aggregate surfacing, accounted for $27 \%$ of all new construction and $24.1 \%$ of all re-roofing projects nationwide. According to the EPDM Roofing Association (ERA 2016) approximately $35 \%$ of new EPDM roofing systems are ballasted, which is assumed in this study to be aggregate surfaced. ${ }^{6}$ In combination, BURs and EPDM with aggregate ballast account for an estimated $14.7 \%$ of new construction and $18.3 \%$ of re-roofing for low-slope roof construction. ${ }^{7}$ However, usage of roofing system type varies throughout the country, so regional data will be used to provide estimates specific to the tornado-prone region.

Table 2-3 shows the breakdown of BUR and EPDM roofs (NRCA 2015) for new construction and re-roofing projects for all census divisions (see Figure 2-3) that are partially included in the tornado prone region. The mix of roofing system types can be seen to vary in different parts of the country. Averages are computed by weighting the values for each census division by their relative fraction of Risk Category III and IV buildings in the tornado-prone region. BUR and EPDM roofs with aggregate ballast account for an estimated $12.2 \%$ of new construction and $16.9 \%$ of re-roofing for low-slope roofs in the tornado-prone region. These values are somewhat lower than the estimated national averages of $14.7 \%$ and $18.3 \%$ for new construction and re-roofing, respectively.

\footnotetext{
${ }^{6}$ Single-ply ballasted systems include both aggregate surfaced and paver surfaced. The assumption that all ballasted systems use aggregate is a conservative estimate for this analysis as the paver surfaced systems would not be impacted by the proposed code change.

${ }^{7}$ Although built-up roofs can be surfaced with aggregate, a cap sheet or liquid-applied coating, the analysis conservatively assumes that all built-up roofs are surfaced with aggregate.
} 
Table 2-3 Percentages of Low-Slope Roofing Projects by Roof System Type by Census Division in the Tornado-Prone Region

\begin{tabular}{|c|c|c|c|c|c|c|c|}
\hline \multirow{2}{*}{$\begin{array}{c}\text { Census } \\
\text { Division }\end{array}$} & \multirow[b]{2}{*}{$\begin{array}{l}\text { Fraction } \\
\text { Risk Cat. } \\
\text { III \& IV } \\
\text { Buildings\# } \\
\quad(\%) \\
\end{array}$} & \multicolumn{3}{|c|}{ New Construction (\%) } & \multicolumn{3}{|c|}{ Re-roofing (\%) } \\
\hline & & BUR & EPDM & Total* & BUR & EPDM & Total* \\
\hline US & 100 & 5.2 & 27.1 & 14.7 & 9.9 & 24.1 & 18.3 \\
\hline Mid-Atlantic & 5 & 4.1 & 40.0 & 18.1 & 7.0 & 33.3 & 18.7 \\
\hline South Atlantic & 1 & 9.6 & 14.4 & 14.6 & 13.0 & 11.3 & 17.0 \\
\hline East North Central & 43 & 1.4 & 35.2 & 13.7 & 4.5 & 33.0 & 16.1 \\
\hline East South Central & 16 & 3.8 & 11.0 & 7.7 & 5.5 & 11.1 & 9.4 \\
\hline West North Central & 19 & 3.3 & 45.0 & 19.1 & 12.1 & 52.2 & 30.4 \\
\hline West South Central & 15 & 1.4 & 2.5 & 2.3 & 9.0 & 1.2 & 9.4 \\
\hline \multicolumn{3}{|c|}{ Tornado-Prone Region } & Avg & 12.2 & & Avg & 16.9 \\
\hline \multicolumn{8}{|c|}{$\begin{array}{l}\text { \#Percentage of tornado-prone region Risk Category III/IV buildings } \\
\text { *Assumes } 35 \% \text { of EPDM systems are ballasted } \\
\text { Note: TPO and PVC membranes are excluded because these systems are not typically } \\
\text { surfaced with aggregate. }\end{array}$} \\
\hline
\end{tabular}

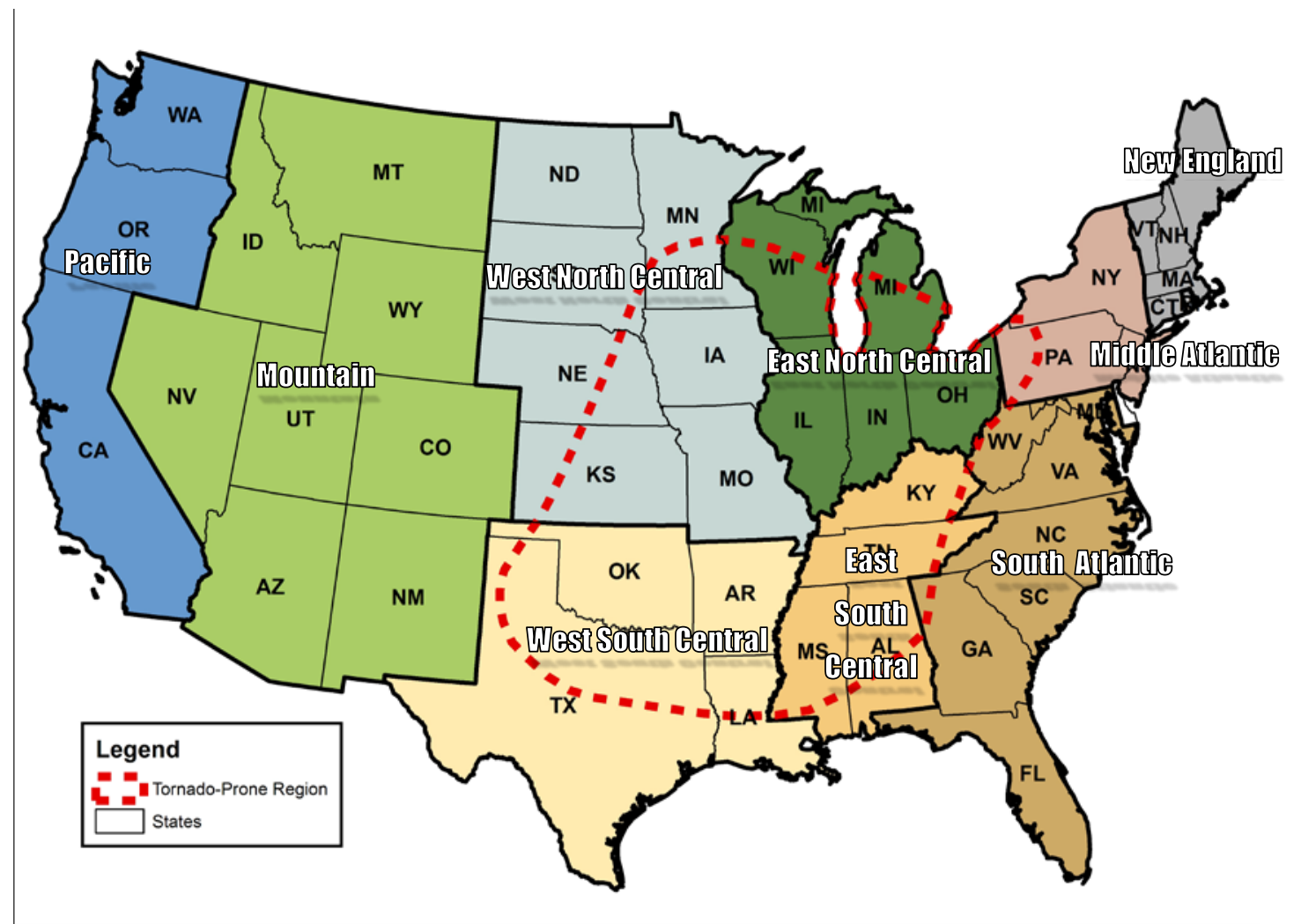

Figure 2-3 Census Divisions ${ }^{8}$

\footnotetext{
${ }^{8}$ Source: NOAA (2016d). Enhancements by NIST.
} 
Based on these estimates of market share for aggregate-surfaced roof types and the number of Risk Category III and IV buildings as a percentage of the total building stock ${ }^{9}$, approximately $0.07 \%$ of all new U.S. roof construction would be potentially impacted and approximately $0.1 \%$ of all U.S. re-roofing projects would potentially be impacted by the proposed code change (see Table 2-4). These numbers change to $0.7 \%$ and $1.0 \%$ of all U.S. roofing construction when excluding residential buildings with less than 50 units, respectively, $0.2 \%$ and $0.3 \%$ of all buildings in the tornado-prone region, respectively, and $2.2 \%$ to $3.0 \%$ of all buildings in the tornado-prone region excluding residential buildings with less than 50 units, respectively.

Table 2-4 Upper Bound Estimate of Percentage of Roof Construction Potentially Impacted by Proposed Code Change

\begin{tabular}{|l|c|c|}
\hline $\begin{array}{c}\text { Number of Risk Category III and IV Buildings in the } \\
\text { Tornado-Prone Region with Low-Slope Roofs having } \\
\text { Aggregate Surfacing }\end{array}$ & $\begin{array}{c}\text { New } \\
\text { Construction }\end{array}$ & $\begin{array}{c}\text { Re- } \\
\text { roofing }\end{array}$ \\
\hline Fraction of U.S. Building Stock & $0.07 \%$ & $0.10 \%$ \\
\hline $\begin{array}{l}\text { Fraction of U.S. Building Stock Excluding Residential } \\
\text { Buildings with < } 50 \text { units }\end{array}$ & $0.7 \%$ & $1.0 \%$ \\
\hline Fraction of Tornado-Prone Region Building Stock & $0.2 \%$ & $0.3 \%$ \\
\hline $\begin{array}{l}\text { Fraction of Tornado-Prone Region Building Stock Excluding } \\
\text { Residential Buildings with < } 50 \text { units }\end{array}$ & $2.2 \%$ & $3.0 \%$ \\
\hline
\end{tabular}

Limiting the building stock data to those buildings that are expected to have a low-slope roof, located within the tornado-prone region, with the Risk Category III or IV designation, and would be constructed using aggregate-surfaced roofing systems if not for the new restriction reduces the estimated fraction of the building stock potentially impacted by the proposed code change to less than $0.1 \%$ of the total U.S. roof construction and less than $3.0 \%$ of the non-low rise residential roof construction within the tornado-prone region.

These results are effectively upper bound estimates; the actual values would be smaller, perhaps substantially so. This is due to limitations of the data and assumptions made in the analysis, all of which tend to bias the final results towards overestimation of the impacts of the proposed code change. These biases, which have been described throughout this chapter, are summarized in the following paragraphs.

\footnotetext{
${ }^{9}$ Assuming the future rate of construction of Risk Category III and IV buildings retains the same proportional mix with other Risk Category buildings as in the existing building stock within the tornado-prone region.
} 
At the beginning of this chapter, five requirements were identified for buildings to be potentially impacted by the proposed code change: (1) located within the tornado-prone region; (2) classified as Risk Category III or IV structures; (3) built with a low-slope roof; (4) not already restricted from using aggregate surfacing based on building height and exposure; and (5) would be constructed or re-roofed using aggregate surfaced roofing systems if not for the new restriction. Biases introduced in each step of the analysis are:

(1) Location within the tornado-prone region: A small part of the tornado-prone region in Mississippi and Alabama is also in the hurricane-prone region. Roofs of all buildings in this overlap region are already prohibited from using aggregate surfacing.

(2) Classification of Risk Category III and IV buildings: The number of buildings from the Hazus database assigned to Risk Categories III and IV is an overestimate due to differences between the occupancy categories defined by IBC and those used in Hazus, and the procedures used to map between the two sets of occupancy definitions.

(3) Built with a low-slope roof: Having no data on the percentage of Risk Category III and IV buildings with low-slope roofs, it was assumed that all of these buildings had low-slope roofs.

(4) Existing IBC prohibition on aggregate surfacing: As described in Section 1.6, IBC Section 1504.8 restricts the use of aggregate surfacing outside of the hurricane-prone region based on design wind speed, mean roof height, and terrain exposure. In the tornado-prone region, this limitation translates to restrictions ranging from buildings of one to 10 stories in height, depending on the exposure category. Since no data are available on the heights and exposures of the Risk Category III and IV buildings, it was assumed that all buildings were low enough not to be subject to the existing restrictions.

(5) Current market share for aggregate surfaced roofs: The available roofing industry market data does not fully differentiate roofing system types by aggregate surfacing. Although built-up roofs can be surfaced with aggregate, a cap sheet or liquid-applied coating, it was assumed that all BUR were surfaced with aggregate. Similarly, while EPDM roofs can use aggregate or pavers for ballast, it was assumed that all singly-ply ballasted systems were surfaced with aggregate (see footnotes 7 and 8).

As demonstrated, the analysis tended to overestimate the number of buildings meeting each of the five requirements, meaning the potential impacts are less than would be inferred from the values in Table 2-4. These results are upper bounds on the estimated impacts.

\subsection{Comparison to the Hurricane-Prone Region}

In addition to comparisons to the U.S. building stock, it is of interest to compare the potential impacts of the proposed change to the impacts of the change to the 2006 IBC that prohibited 
aggregate-surfaced roofs for all Risk Category buildings in hurricane-prone regions. Figure 2-4 shows both the proposed tornado-prone region as well as the hurricane-prone region (hatch marked contour). Although the tornado-prone region covers a larger land area than the hurricaneprone region, the map does not account for the densities of building stock or the fact that all building types in the hurricane-prone region are impacted by the roof aggregate prohibition, whereas the proposed code change in the tornado-prone region applies only to Risk Category III and IV buildings A small part of the tornado prone region, in central Mississippi and Alabama, is also part of the hurricane-prone region, so the proposed code change would have no effect there as aggregate-surfaced roofs are already prohibited.

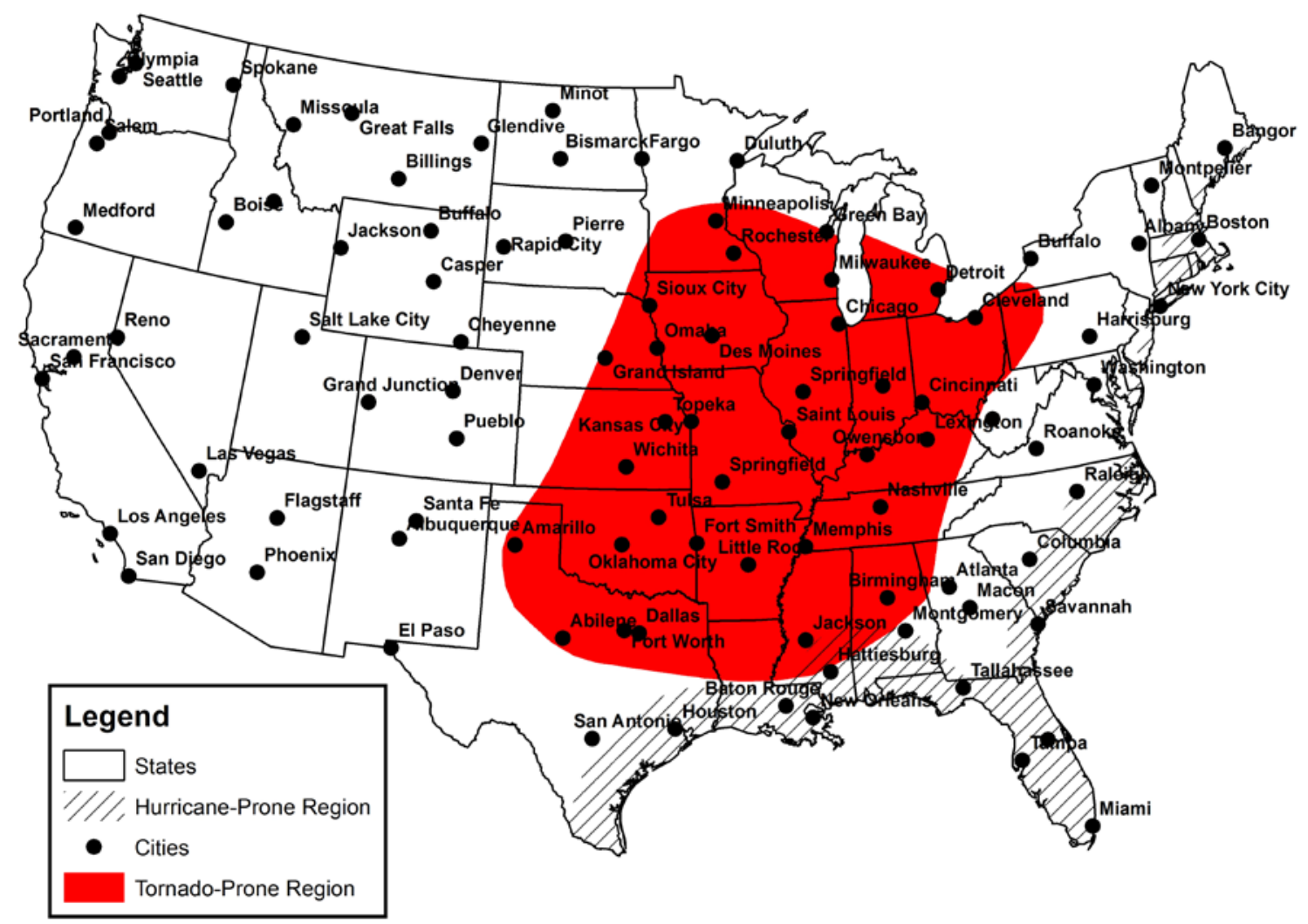

Figure 2-4 Map of Existing Hurricane-Prone and Proposed Tornado-Prone Regions

Figure 2-5 shows the county level total building stock data for the contiguous U.S. along with the outline of both regions. The hurricane-prone region (seaward to the red dotted line) includes 415 counties compared to the tornado-prone region's 1456 counties. However, the hurricane-prone region appears to have a heavier building density. Given a potentially higher building density along the coasts combined with the prohibition on aggregate for all risk categories, not just Risk 
Category III and IV, it would be expected that the number of potentially impacted buildings may be as large or larger for the hurricane-prone region than those in the tornado-prone region.

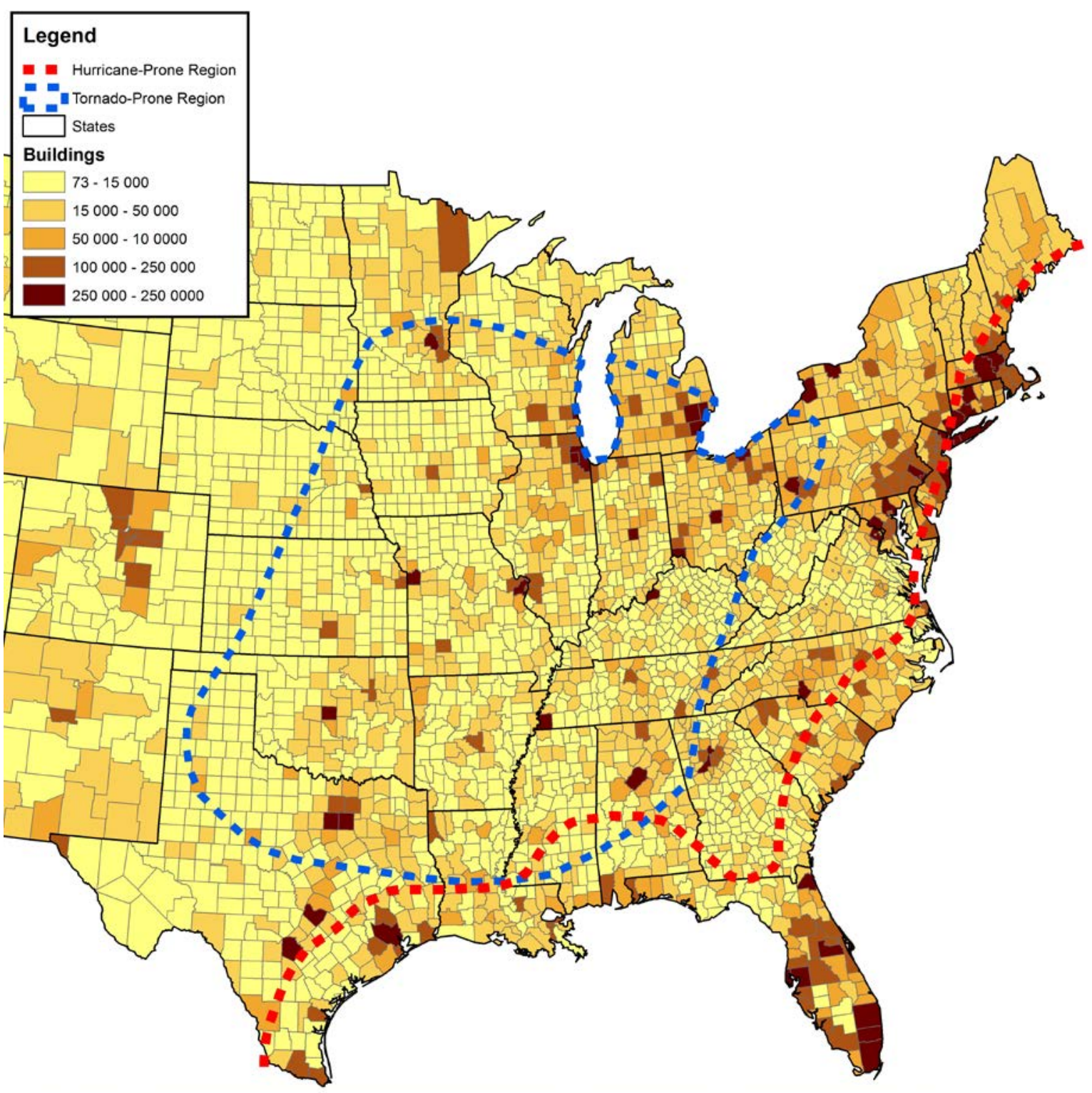

Figure 2-5 Building Stock Counts by County with Hurricane and Tornado-Prone Regions

Table 2-5 shows that the hurricane-prone region has fewer Risk Categories III and IV buildings (457 483) than the tornado-prone region (606 552). However, the prohibition on aggregate surfaced roofs applies to all buildings of all four risk categories in the hurricane-prone region, which can be estimated using the total building stock excluding residential buildings with fewer than 50 units. The number of buildings potentially impacted by the roof aggregate ban in hurricane-prone regions totals 2461185. 
Table 2-5 Existing Building Stock by Occupancy - Tornado- vs Hurricane-Prone Region

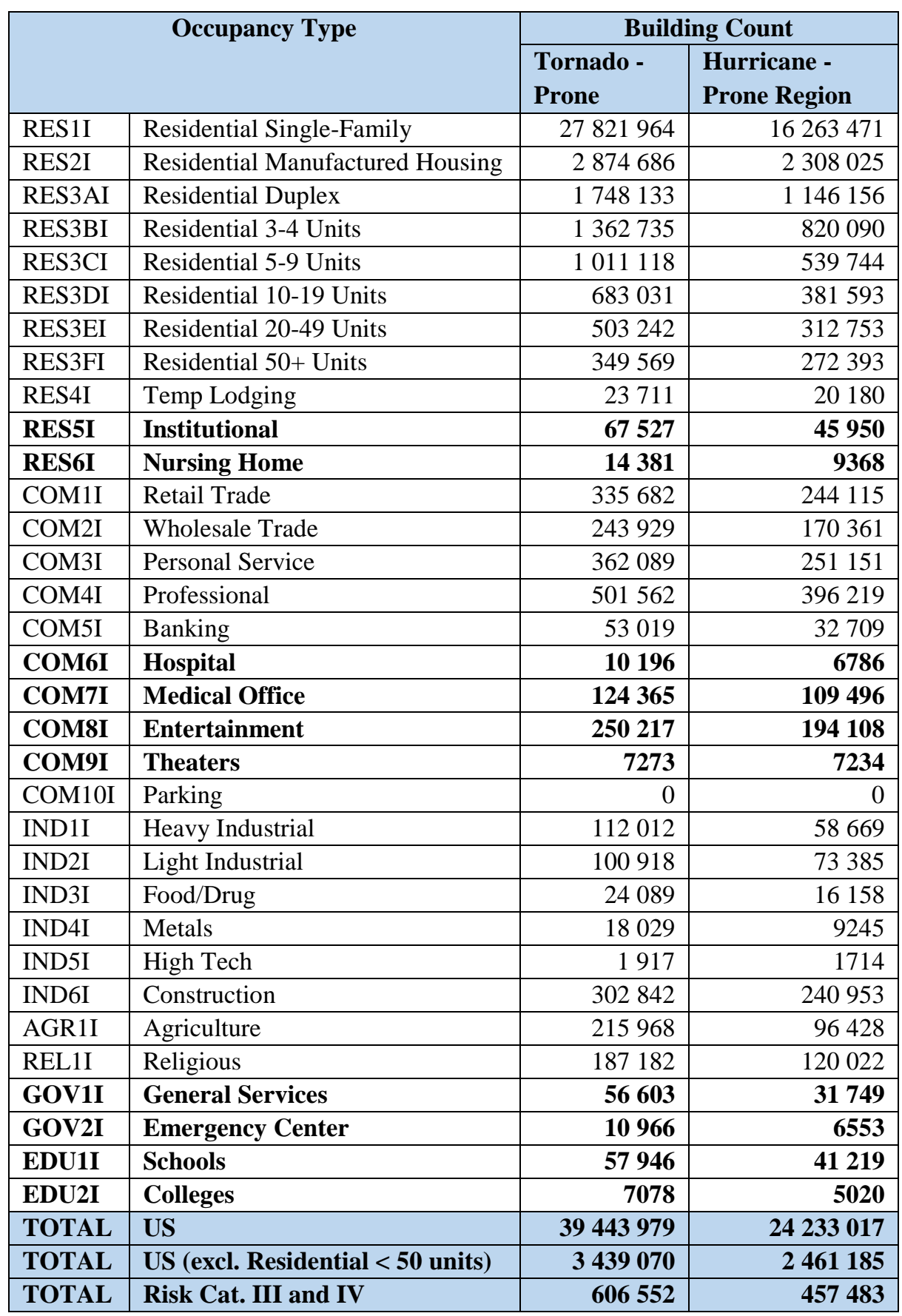

As in the case of the tornado-prone region, the accurate number of impacted buildings needs to account for the fact that aggregate surfacing is used for only a fraction of all low-slope roofing projects, which varies by Census Division. Table 2-6 shows the percentages of low-slope roofing work by BUR and EDPM roof systems. Assuming approximately $35 \%$ of EDPM roof systems are aggregate ballasted, Table 2-6 also shows that the average fraction of roofing construction in 
the hurricane-prone region that would have used aggregate if not for the adopted ban in the IBC is $14.0 \%$ for new construction and $16.9 \%$ for re-roofing, leading to the total number of impacted buildings of 344566 and 415 940, respectively, which is $0.31 \%$ and $0.38 \%$, respectively, of the entire U.S. building stock (3.4\% and $4.1 \%$, respectively, if excluding residential buildings with less than 50 units). In comparison, similar estimates of the potential effects of the proposed code change in the tornado-prone region (from Table 2-5) are much smaller, $0.07 \%$ of all new U.S. roof construction and $0.1 \%$ of all U.S. re-roofing projects (0.7 \% and $1.0 \%$ respectively, if excluding residential buildings with less than 50 units).

Table 2-6 Percentages of Low-Slope Roofing Projects by Roof System Type by Census Division in Hurricane-Prone Region

\begin{tabular}{|c|c|c|c|c|c|c|c|}
\hline \multirow{2}{*}{$\begin{array}{l}\text { Census } \\
\text { Division }\end{array}$} & \multirow{2}{*}{$\begin{array}{c}\text { Fraction } \\
\text { All } \\
\text { Buildings\# } \\
(\%)\end{array}$} & \multicolumn{3}{|c|}{ New Construction (\%) } & \multicolumn{3}{|c|}{ Reroofing (\%) } \\
\hline & & BUR & EPDM & Total* & BUR & EPDM & Total* \\
\hline US & 100 & 5.2 & 27.1 & 14.7 & 9.9 & 24.1 & 18.3 \\
\hline New England & 20.2 & 1.5 & 51.5 & 19.5 & 2.0 & 58.3 & 22.4 \\
\hline Mid-Atlantic & 16.9 & 4.1 & 40.0 & 18.1 & 7.0 & 33.3 & 18.7 \\
\hline South Atlantic & 43.5 & 9.6 & 14.4 & 14.6 & 13.0 & 11.3 & 17.0 \\
\hline East South Central & 4.4 & 3.8 & 11.0 & 7.7 & 5.5 & 11.1 & 9.4 \\
\hline West South Central & 15.0 & 1.4 & 2.5 & 2.3 & 9.0 & 1.2 & 9.4 \\
\hline \multicolumn{3}{|c|}{ Hurricane-Prone Region } & Avg & 14.0 & & Avg & 16.9 \\
\hline
\end{tabular}

Assuming new construction and re-roofing occur at rates proportional to the applicable elements of existing building stock in each of the two regions, the existing ban on aggregate-surfaced roofs in the hurricane-prone region applies to more than four times as much roof construction as the proposed restrictions in the tornado-prone region. This is a lower bound estimate of the ratio between the impacts in the hurricane prone versus tornado prone region, the actual ratio is likely much higher, for several reasons. Let's again consider the biases in analyses of the five requirements for estimating impacts in the tornado-prone region, but in comparison with how the data limitations and assumptions bias the estimates in the hurricane-prone region.

(1) Location within the tornado-prone region: A small part of the tornado-prone region in Mississippi and Alabama is also in the hurricane-prone region. Roofs of all buildings in this overlap region are already prohibited from using aggregate surfacing, so the estimated impacts in the tornado-prone regions are slightly too large.

(2) Classification of Risk Category III and IV buildings: In the tornado-prone region, the mapping between Hazus occupancy types and IBC Risk Category requirements led to an overestimate of the number of Risk Category III and IV buildings. However, since the 
prohibition on aggregate in the hurricane-prone region applies to all Risk Category buildings, the building stock data is used directly, with no overestimation bias.

(3) Built with a low-slope roof: No difference between assumptions for tornado- and hurricane-prone regions.

(4) Existing IBC prohibition on aggregate surfacing: In the tornado-prone region, due to data limitations, it was assumed that all buildings were low enough not to be subject to the existing restrictions based on height and terrain exposure, leading to an overestimate. However, in the hurricane-prone region, the prohibition on aggregate applies to all buildings regardless of height and exposure. Therefore, the building stock data is used directly, with no overestimation bias.

(5) Current market share for aggregate surfaced: The NRCA regional roofing industry data used to estimate the market share of aggregate-surfaced roofs includes the effects of the prohibition on aggregate in the hurricane prone region that was introduced in the 2006 IBC. Therefore, in census divisions which include parts of the hurricane-prone region, roofs that would otherwise have been constructed with aggregate-surfacing have switched to other roof surfacing systems. This perhaps explains why the total estimated market share for aggregatesurfaced roofs in new construction in the three census divisions that are partly in the hurricane-prone region is smaller than in any other census divisions east of the continental divide. This underestimation of market share introduces the same biases in both the hurricane- and tornado-prone region. However, most (62 \%) of the Risk Category III and IV buildings in the tornado-prone region are located in the Midwest and Great Plains states, represented in the East North Central and West North Central census divisions (see Figure 23 and Table 2-4), which are not subject to this particular bias.

One additional assumption also biases the results towards relative overestimation of impacts in the tornado-prone region compared to the hurricane-prone region. It was assumed that the proportion of existing construction of potentially impacted buildings would continue in relation to such proportions in the existing building stock. However, no assumption was made as to the rate of this construction. The value for new construction along the East and Gulf Coasts coastal areas exceed those in the interior of the country, biasing the comparative analysis to underestimate impacts in hurricane- versus tornado-prone regions. The value of private non-residential construction put in place is greatest for the West South Central, South Atlantic, and Middle Atlantic census divisions, accounting for $24 \%, 16 \%$, and $13 \%$ of the U.S. total in 2015, respectively (Census 2016).

Of the six factors described above, five are biased toward overestimation of the number of potentially impacted buildings in the tornado-prone region compared to the hurricane-prone region (and the remaining factor has the same relative biases for both regions). Therefore, the estimate that the impact of the potential code change in the tornado-prone region is less than one 
fourth of the current impacts of aggregate restrictions in the hurricane-prone region is an upper bound estimate. The relative impact would be even smaller. 


\section{Costs of Alternative Roofing Systems}

To quantify the potential economic impacts of adopting the proposed change to the IBC, it is necessary to estimate the costs of installing a low-slope roof with and without the use of aggregate surfacing. The cost comparisons are dependent on the roof deck, roofing system type, and the selected top layer of the roofing system.

\subsection{Alternative Roof Systems}

There are a wide range of low-slope roofing systems, including built-up, single-ply membrane, and liquid-applied systems. To condense the number of systems for comparison, only the most commonly used roofing systems were considered, those that use aggregate and commonly available alternatives that do not. This study considers three different types of roofing structural support with at least two roofing system options for each, one with aggregate surfacing as the baseline system and one or more alternatives that do not include aggregate. Table 3-1 shows the seven roofing systems considered, including two built-up roof deck, two concrete deck, and three steel deck systems. It is assumed that the roof deck is selected before selecting the roofing system.

Table 3-1 Roofing Assembly Alternatives

\begin{tabular}{lll}
\hline Surfacing & Roof Deck & Roofing System \\
\hline \multirow{2}{*}{ Built-Up Roof } & Any Deck Type & $\begin{array}{l}\text { 4-ply membrane with aggregate surfacing } \\
\text { 3-ply membrane with cap sheet }\end{array}$ \\
\hline \multirow{2}{*}{ Single-Ply } & Concrete Deck & $\begin{array}{l}\text { Aggregate ballasted } \\
\text { Fully adhered }\end{array}$ \\
\cline { 2 - 3 } & Steel Deck & $\begin{array}{l}\text { Aggregate ballasted } \\
\text { Mechanically attached membrane } \\
\text { Fully adhered }\end{array}$ \\
\hline
\end{tabular}

\subsubsection{Built-Up Roof Systems}

A built-up roof (BUR) system is composed of alternating layers of bitumen (typically asphalt, coal tar or cold-applied adhesives) and reinforcing fabrics (roofing felt) with a surfacing (aggregate or mineral surfaced cap sheets), or a smooth surfacing (hot asphalt glaze coat, aluminum-pigmented asphalt, or elastomeric coating). The two built-up roof systems selected for this study are a (1) traditional 4-ply hot asphalt with an aggregate surfacing and (2) traditional 3ply hot asphalt with a mineral surface cap sheet. Figure 3-1 shows an example of a hot asphalt system with aggregate surfacing (left) and a hot asphalt system with a cap sheet (right). However, a cap sheet surfacing decreases the weight needed to be supported by the roof deck. 

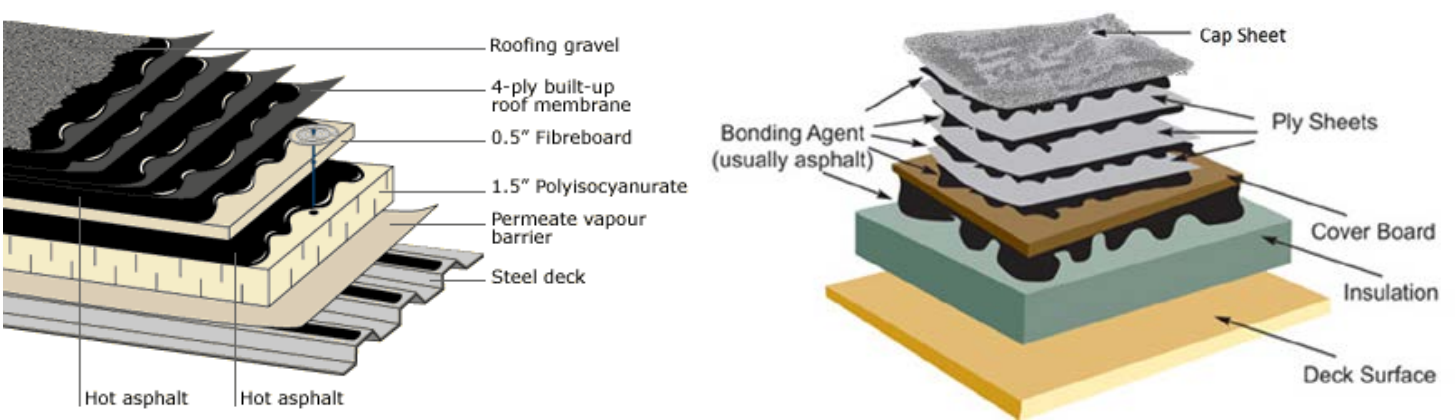

Figure 3-1 Example Built-Up Roof Asphalt with Aggregate (left) ${ }^{10}$ and Cap Sheet (right) ${ }^{11}$

For a cost comparison of the BUR systems, only the number of ply sheets and surfacing are considered because the remainder of the assembly will be the same for the two options, including the deck and insulation. ${ }^{12}$

\subsubsection{Single-Ply Membrane Roof Systems}

A single-ply membrane roof system includes a single layer of material instead of multiple layers as in built-up roof systems. Single-ply membranes include thermosets and thermoplastics. The most common thermoset membrane is EPDM while common thermoplastics are polyvinyl chloride (PVC) and thermoplastic polyolefin (TPO). Single-ply membranes can be attached to the roof deck through several methods as shown in Figure 3-2: loosely laid and aggregate ballasted (left), fully adhered (center), and mechanically attached (right).

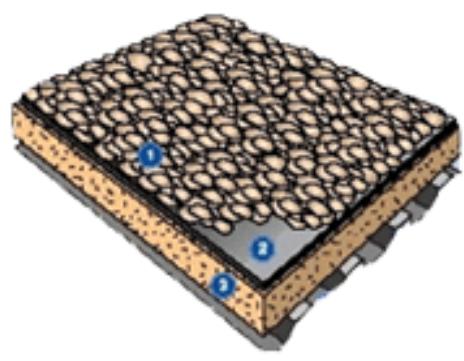

Ballasted

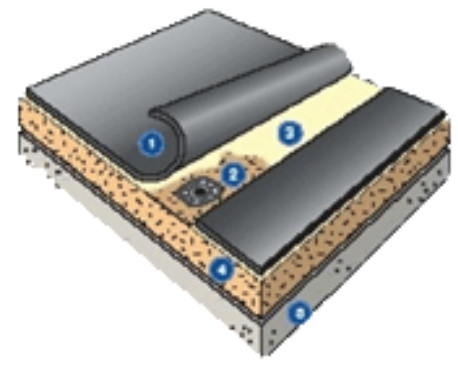

Fully Adhered

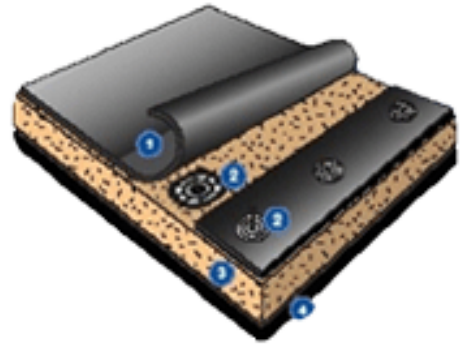

Mechanically Attached

Figure 3-2 Example Single-Ply Roof with Aggregate Ballast (left), Fully Adhered (center), and Mechanically Attached (right) ${ }^{13}$

The three single-ply systems selected for this study are a (1) EPDM with aggregate ballast, (2) EPDM fully adhered, and (3) EPDM mechanically fastened. EPDM is selected because it is commonly ballasted, whereas PVC and TPO are typically adhered or mechanically attached.

\footnotetext{
${ }^{10}$ Image Source: http://www.staterfg.com/wp-content/uploads/2013/07/systemA21.gif

${ }^{11}$ Image Source: http://www.fromridgetoeave.com/top-tips-for-mounting-pv-on-low-slope-roofing/

${ }^{12}$ Cap sheets can be traditional asphalt/mineral surfaced or modified bituminous.

${ }^{13}$ Image Source: ERA 2016.
} 
Aggregate Ballasted EPDM is loose laid with aggregate (or pavers) spread out on the membrane to keep it from being uplifted in high winds. Fully adhered EPDM is attached with adhesives. Mechanically attached EPDM is loose laid with fasteners attaching the membrane to the roof deck. $^{14}$

Each of these options will be considered for both a concrete roof deck and steel roof deck. The EPDM membrane is assumed to be $1.143 \mathrm{~mm}$ (45 mil) for all three membrane securement options and roof decks (i.e., concrete or steel). The aggregate ballasted option assumes $49 \mathrm{~kg} / \mathrm{m}^{2}$ $\left(10 \mathrm{lb} / \mathrm{ft}^{2}\right)$ of aggregate with a protection mat regardless of the roof deck. To make comparisons to the aggregate ballasted system, the fully adhered EPDM will need to include the adhesive between the membrane and insulation and attaching the insulation (with either adhesives or fasteners) in cost estimates.

Each of the five roof covering alternatives are mapped to the RS Means cost databases as shown in Table 3-2, which is based on UNIFORMAT II (standard for classifying building elements) for assembly cost data and MASTERFORMAT (standard for classifying building products) for unit cost data.

Table 3-2 Roofing Systems and Roof Components in RS Means Databases

\begin{tabular}{|l|l|l|l|}
\hline \multicolumn{2}{|l|}{ Roofing Assembly } & UNIFORMAT II & RS Means Description \\
\hline Asphalt & $\begin{array}{l}\text { 4-ply w/ aggregate } \\
\text { surfacing }\end{array}$ & B30101051600 & $\begin{array}{l}\text { Roofing, asphalt flood coat, gravel, base } \\
\text { sheet, 4 plies 15\# asphalt felt, mopped }\end{array}$ \\
\cline { 2 - 4 } & 3-ply w/ cap sheet & B30101055700 & $\begin{array}{l}\text { Roofing, asphalt mineral surface, roll, 3 } \\
\text { plies glass fiber felt (Type IV), 1 ply } \\
\text { mineral surfaced selvage roofing, lap 1.9", } \\
\text { mopped }\end{array}$ \\
\hline $\begin{array}{l}\text { Single-Ply } \\
\text { EPDM }\end{array}$ & $\begin{array}{l}\text { Aggregate } \\
\text { ballasted }\end{array}$ & B30101202100 & $\begin{array}{l}\text { Roofing, single ply membrane, EPDM, 45 } \\
\text { mils, loosely laid, stone ballast (10 PSF) }\end{array}$ \\
\cline { 2 - 5 } & Fully adhered & B30101202000 & $\begin{array}{l}\text { Roofing, single ply membrane, EPDM, } \\
\text { 45mils, fully adhered }\end{array}$ \\
\cline { 2 - 5 } & $\begin{array}{l}\text { Mechanically } \\
\text { attached }\end{array}$ & B30101202200 & $\begin{array}{l}\text { Roofing, single ply membrane, EPDM, 45 } \\
\text { mils, mechanically fastened, batten strips }\end{array}$ \\
\hline Roofing Component & MASTERFORMAT & RS Means Description \\
\hline $\begin{array}{l}\text { Protection } \\
\text { Mat }\end{array}$ & 075510100130 & $\begin{array}{l}\text { Protected membrane roofing components, } \\
\text { filter fabric }\end{array}$ \\
\hline $\begin{array}{l}\text { Insulation } \\
\text { Installation }\end{array}$ & $\begin{array}{l}\text { Installation } \\
\text { fastener }\end{array}$ & 072216103010 & 4” Coated Screws (1 per ft ${ }^{2}$ ) \\
\hline
\end{tabular}

\footnotetext{
${ }^{14}$ Mechanically attached EPDM to concrete decks is uncommon because there are less costly alternatives, and is typical used only under special circumstances.
} 


\subsection{Roofing Cost Data, Comparisons, and Implications}

The mapping of the seven roofing assemblies to the RS Means cost data (based on UNIFORMAT II and MASTERFORMAT) allows for comparisons across alternative systems given the assumed roof deck. Table 3-3 shows the national average cost per unit of area for each of the roofing systems.

Table 3-3 Roofing System Cost Data - National Average

\begin{tabular}{lllc}
\hline \multicolumn{2}{l}{ Roofing System } & & $\$ / \mathrm{m}^{2}\left(\$ / \mathrm{ft}^{2}\right)$ \\
\hline $\begin{array}{l}\text { Built-Up } \\
\text { Roof }\end{array}$ & Traditional & 4-ply membrane with aggregate surfacing & $\$ 36.27(\$ 3.37)$ \\
& Hot Asphalt & 3-ply membrane with cap sheet & $\$ 31.75(\$ 2.95)$ \\
\hline \multirow{3}{*}{$\begin{array}{l}\text { Single-Ply } \\
\text { EPDM }\end{array}$} & & EPDM - Aggregate ballasted & $\$ 17.11(\$ 1.59)$ \\
\cline { 3 - 4 } & \multirow{2}{*}{ Steel Deck } & EPDM - Fully adhered & $\$ 25.83(\$ 2.40)$ \\
\cline { 3 - 4 } & & EPDM - Mechanically attached membrane & $\$ 17.11(\$ 1.59)$ \\
& & EPDM - Fully adhered & $\$ 25.83(\$ 1.54)$ \\
\hline
\end{tabular}

For a built-up roof, the system with aggregate surfacing (B30101051600) leads to higher costs than the alternative system that replaces the aggregate with a cap sheet (B30101055700). These additional costs are driven by slightly higher material costs $\left(\$ 0.54 / \mathrm{m}^{2}\right.$ or $\left.\$ 0.05 / \mathrm{ft}^{2}\right)$ and significantly higher labor costs $\left(\$ 3.98 / \mathrm{m}^{2}\right.$ or $\left.\$ 0.37 / \mathrm{ft}^{2}\right)$.

For the single-ply system for a building with a steel deck, the mechanically attached EPDM (B30101202200) is the less expensive system $\left(\$ 16.58 / \mathrm{m}^{2}\right.$ or $\left.\$ 1.54 / \mathrm{ft}^{2}\right)$ followed by the aggregate ballasted EPDM system ( $\$ 17.11 / \mathrm{m}^{2}$ or $\$ 1.59 / \mathrm{ft}^{2}$ ) because the ballasted system (B30101202100) uses a protection mat $(075510100130)$, which adds $\$ 2.15 / \mathrm{m}^{2}\left(\$ 0.20 / \mathrm{ft}^{2}\right)$. The ballasted system assumes no additional cost to the roof structure to handle the additional weight of the aggregate, which may vary depending on whether the deck is steel or concrete. The materials are less costly, but labor costs are higher for the mechanically attached assembly.

The most expensive single-ply system is fully adhered EPDM $\left(\$ 25.83 / \mathrm{m}^{2}\right.$ or $\left.\$ 2.40 / \mathrm{ft}^{2}\right)$, which includes the fully adhered single-ply EPDM assembly (B30101202000) and the cost of attaching the insulation under the single-ply (072216103010). Only the cost of attaching the insulation is required because the insulation itself would be included in the ballasted and mechanically attached systems, and would not be independently fastened to the roof deck. The most common insulation attachment method is foam ribbon adhesive. However, data is not available for the adhesive, leading to the assumption that insulation is attached using coated screws, which is expected to be more expensive than foam ribbon adhesive and should lead to a conservative (higher) cost estimate. The additional $\$ 8.72 / \mathrm{m}^{2}$ or $\$ 0.81 / \mathrm{ft}^{2}$ (51\%) relative to the ballasted system are a result of higher costs for both the materials and labor. 
Given that material and labor costs may vary significantly by location, these same cost estimates are completed for the 33 metropolitan areas shown in Figure 2-1. Table 3-4 shows the cost for five roofing systems, two BUR and three EDPM, across 33 cities throughout the tornado-prone region. Regardless of the location, the optimal choices remain the same. The built-up system with the cap sheet saves between $\$ 3.01 / \mathrm{m}^{2}\left(\$ 0.28 / \mathrm{ft}^{2}\right)$ and $\$ 5.92 / \mathrm{m}^{2}\left(\$ 0.55 / \mathrm{ft}^{2}\right)$ relative to the built-up system with aggregate. The mechanically attached EPDM system lowers costs by $\$ 0.11 / \mathrm{m}^{2}\left(\$ 0.01 / \mathrm{ft}^{2}\right)$ to $\$ 1.08 / \mathrm{m}^{2}\left(\$ 0.10 / \mathrm{ft}^{2}\right)$ while the fully adhered EPDM system increases costs by $\$ 6.14 / \mathrm{m}^{2}$ ( $\left.\$ 0.57 / \mathrm{ft}^{2}\right)$ to $\$ 10.87 / \mathrm{m}^{2}\left(\$ 1.01 / \mathrm{ft}^{2}\right)$ relative to the aggregate ballasted EPDM system. Note that the mechanically attached EPDM system cost estimates only apply to assemblies with steel decks.

Based on these results, the only new roof construction or re-roofing that would be negatively impacted from a construction cost perspective by the code change are those that would have otherwise installed a ballasted single-ply membrane on a concrete deck. Any installation of BUR systems would realize lower costs using a cap sheet instead of aggregate surfacing, which lowers the fraction of Risk Category III/IV buildings that could potentially realize higher costs from the code change proposal to under $10 \%$ for both new construction (9.8\%) and reroofing projects (9.7\%). This is a drop from $0.2 \%$ for new construction and $0.3 \%$ for reroofing to less than $0.2 \%$ of the total building stock in the tornado-prone region and from $2.2 \%$ to $3.0 \%$ to $1.7 \%$ of the non-low rise residential roof construction in the tornado-prone region. Additionally, any roof assemblies with steel decks would lower costs using a mechanically attached EPDM instead of EPDM with aggregate ballast, further lowering the number of roof construction negatively impacted by the change in the code to restrict roof aggregate. 
Table 3-4 Assembly Cost by Location in Tornado-Prone Region

\begin{tabular}{|c|c|c|c|c|c|c|}
\hline \multirow{2}{*}{\multicolumn{2}{|c|}{ Location }} & \multicolumn{5}{|c|}{ Cost $\left(\$ / f^{2}\right)^{2}$} \\
\hline & & \multirow{2}{*}{$\begin{array}{l}\begin{array}{l}\text { Asphalt - } \\
\text { Aggregate } \\
\text { Surfacing }\end{array} \\
3.37\end{array}$} & \multirow{2}{*}{$\begin{array}{r}\begin{array}{l}\text { Asphalt - } \\
\text { Cap Sheet }\end{array} \\
2.95\end{array}$} & $\begin{array}{l}\text { EPDM - } \\
\text { Aggregate } \\
\text { Ballasted }\end{array}$ & $\begin{array}{l}\text { EPDM - } \\
\text { Mechanically } \\
\text { Attached* }\end{array}$ & $\begin{array}{l}\text { EPDM - } \\
\text { Fully } \\
\text { Adhered }\end{array}$ \\
\hline \multicolumn{2}{|c|}{ National Average } & & & 1.59 & 1.54 & 2.40 \\
\hline $\mathrm{AL}$ & Birmingham & 3.18 & 2.79 & 1.54 & 1.47 & 2.30 \\
\hline AR & Ft Smith & 2.70 & 2.42 & 1.37 & 1.27 & 1.95 \\
\hline AR & Little Rock & 2.64 & 2.35 & 1.32 & 1.23 & 1.89 \\
\hline IA & Des Moines & 2.99 & 2.65 & 1.46 & 1.38 & 2.14 \\
\hline IA & Sioux City & 2.92 & 2.60 & 1.47 & 1.38 & 2.13 \\
\hline IL & Chicago & 4.05 & 3.49 & 1.82 & 1.81 & 2.83 \\
\hline IL & Springfield & 3.64 & 3.17 & 1.72 & 1.67 & 2.59 \\
\hline IN & Indianapolis & 3.10 & 2.74 & 1.53 & 1.44 & 2.23 \\
\hline KS & Topeka & 2.91 & 2.58 & 1.43 & 1.36 & 2.12 \\
\hline KS & Wichita & 2.64 & 2.36 & 1.33 & 1.24 & 1.92 \\
\hline KY & Lexington & 3.18 & 2.81 & 1.57 & 1.48 & 2.28 \\
\hline KY & Owensboro & 3.17 & 2.79 & 1.53 & 1.46 & 2.27 \\
\hline MI & Detroit & 3.57 & 3.11 & 1.66 & 1.62 & 2.54 \\
\hline MN & Minneapolis & 3.89 & 3.36 & 1.77 & 1.75 & 2.76 \\
\hline MN & Rochester & 3.52 & 3.09 & 1.69 & 1.62 & 2.52 \\
\hline $\mathrm{MO}$ & Kansas City & 3.33 & 2.90 & 1.52 & 1.50 & 2.34 \\
\hline $\mathrm{MO}$ & Springfield & 3.04 & 2.69 & 1.48 & 1.40 & 2.19 \\
\hline $\mathrm{MO}$ & St. Louis & 3.45 & 3.01 & 1.61 & 1.57 & 2.45 \\
\hline MS & Jackson & 2.82 & 2.49 & 1.38 & 1.31 & 2.03 \\
\hline $\mathrm{NE}$ & Grand Island & 3.03 & 2.69 & 1.49 & 1.41 & 2.18 \\
\hline $\mathrm{NE}$ & Omaha & 3.01 & 2.65 & 1.44 & 1.38 & 2.16 \\
\hline $\mathrm{OH}$ & Cincinnati & 3.13 & 2.76 & 1.52 & 1.45 & 2.25 \\
\hline $\mathrm{OH}$ & Cleveland & 3.66 & 3.21 & 1.74 & 1.68 & 2.62 \\
\hline $\mathrm{OK}$ & Oklahoma City & 2.88 & 2.56 & 1.42 & 1.34 & 2.08 \\
\hline$\overline{\mathrm{OK}}$ & Tulsa & 2.82 & 2.51 & 1.41 & 1.32 & 2.05 \\
\hline TN & Memphis & 2.86 & 2.54 & 1.41 & 1.34 & 2.07 \\
\hline TN & Nashville & 2.78 & 2.47 & 1.36 & 1.29 & 2.00 \\
\hline $\mathrm{TX}$ & Abilene & 2.85 & 2.53 & 1.42 & 1.33 & 2.06 \\
\hline $\mathrm{TX}$ & Amarillo & 2.75 & 2.44 & 1.37 & 1.28 & 1.98 \\
\hline $\mathrm{TX}$ & Dallas & 2.74 & 2.42 & 1.34 & 1.27 & 1.97 \\
\hline $\mathrm{TX}$ & Ft Worth & 2.73 & 2.42 & 1.33 & 1.26 & 1.97 \\
\hline WI & Green Bay & 3.28 & 2.89 & 1.62 & 1.52 & 2.34 \\
\hline WI & Milwaukee & 3.57 & 3.11 & 1.67 & 1.63 & 2.54 \\
\hline \multicolumn{2}{|c|}{ Average } & 3.12 & 2.75 & 1.51 & 1.44 & 2.24 \\
\hline \multicolumn{2}{|c|}{ Minimum } & 2.64 & 2.35 & 1.32 & 1.23 & 1.89 \\
\hline \multicolumn{2}{|c|}{ Maximum } & 4.05 & 3.49 & 1.82 & 1.81 & 2.83 \\
\hline \multicolumn{2}{|c|}{ Standard Deviation } & 0.37 & 0.30 & 0.14 & 0.15 & 0.25 \\
\hline
\end{tabular}




\subsection{Examples: 5-Story Hospital and 2-Story High School}

The costs per unit of roof area does not articulate the magnitude of the cost impacts of constructing an entire building. For this reason, two examples are developed to provide perspective. The Department of Energy (DOE) Commercial Reference Building for Hospitals and High Schools (DOE 2016), shown in Figure 3-3 and Figure 3-4, respectively, have been selected, with the resulting cost estimates shown in Table 3-5.

\section{Table 3-5 Example: Roofing System Costs of 5-Story Hospital - National Average}

\begin{tabular}{|c|c|c|c|c|}
\hline \multirow{2}{*}{$\begin{array}{l}\text { Building } \\
\text { Prototype }\end{array}$} & \multirow[t]{2}{*}{ Roofing System } & \multicolumn{3}{|c|}{ Roofing Costs by Building and Roofing System } \\
\hline & & $\begin{array}{l}\text { Roofing Cost } \\
\text { per } \mathbf{m}^{2}\left(\mathrm{ft}^{2}\right)\end{array}$ & $\begin{array}{c}\text { Total } \\
\text { Roofing Cost }\end{array}$ & $\begin{array}{l}\text { Percent of } \\
\text { Building Cost }\end{array}$ \\
\hline \multirow[t]{2}{*}{ Hospital* } & EPDM - Aggregate ballasted & $\$ 17.11(\$ 1.59)$ & $\$ 63998$ & $0.12 \%$ \\
\hline & EPDM - Fully adhered & $\$ 25.83(\$ 2.40)$ & $\$ 96600$ & $0.19 \%$ \\
\hline \multirow[t]{2}{*}{ High School** } & EPDM - Aggregate ballasted & $\$ 17.11(\$ 1.59)$ & $\$ 203711$ & $0.85 \%$ \\
\hline & EPDM - Fully adhered & $\$ 25.83(\$ 2.40)$ & $\$ 307488$ & $1.28 \%$ \\
\hline & \multicolumn{4}{|c|}{$\begin{array}{l}* \text { Total cost of constructing hospital = } \$ 51.7 \text { million } \\
* * \text { Total cost of constructing high school = } \$ 24.0 \text { million } \\
\text { NA = Data Not Available }\end{array}$} \\
\hline
\end{tabular}

The hospital has 5-stories, $22428 \mathrm{~m}^{2}$ (241 $\left.410 \mathrm{ft}^{2}\right)$ of conditioned floor area, and $3739 \mathrm{~m}^{2}$ (40 $250 \mathrm{ft}^{2}$ ) of roof area. Assuming a concrete deck with a single-ply membrane roofing system, the fully adhered EPDM system increases costs by \$34 615 relative to the aggregate ballasted system. However, based on the RS Means Square Foot Cost Estimator (SFCE) (RS Means 2016b) for a hospital with the characteristics shown in Figure 3-3, the total cost of construction would be approximately $\$ 51.7$ million based on national average cost data. The roofing costs are a fraction of a percent of the total costs of constructing the hospital, with the difference between the aggregate ballasted and mechanically attached membrane being nearly indistinguishable. The additional costs of the fully adhered membrane lead to an increase of $0.07 \%$ in total costs. Since the roofing costs are mostly insignificant relative to the cost of constructing the building, an increase due to alternative roof systems does not have detrimental impacts on the total cost to the building owner. 

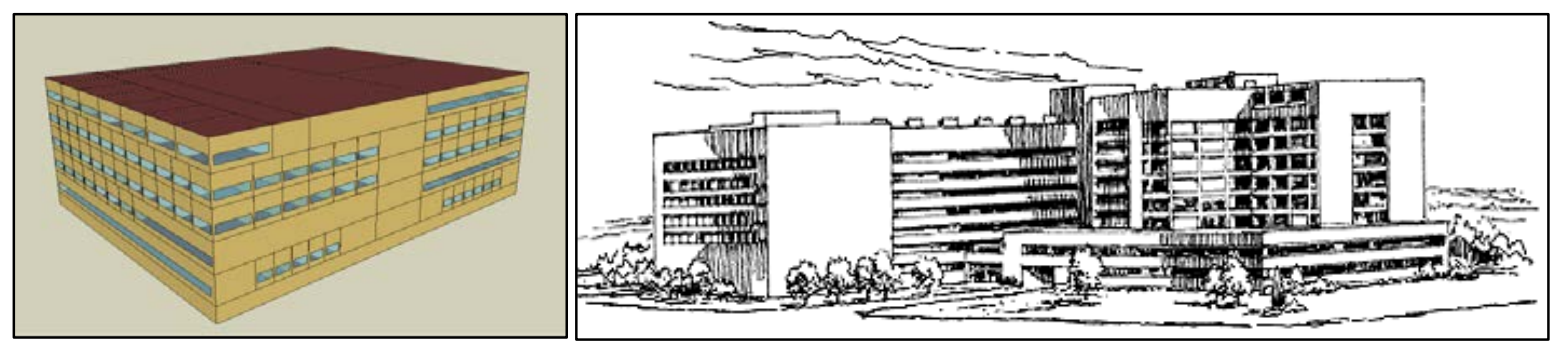

Figure 3-3 Representations of 5-Story Hospital: DOE (left) ${ }^{15}$ and RS Means (right) ${ }^{16}$

The high school has 2-stories, $19592 \mathrm{~m}^{2}\left(210887 \mathrm{ft}^{2}\right)$ of conditioned floor area, and $9796 \mathrm{~m}^{2}$ (128 $120 \mathrm{ft}^{2}$ ) of roof area. Assuming a concrete deck with a single-ply membrane roofing system, the fully adhered EPDM system increases costs by \$103 777 relative to the aggregate ballasted system. However, based on the RS Means SFCE (RS Means 2016b) for a high school with the characteristics shown in Figure 3-4, the total cost of construction would be approximately $\$ 24.0$ million based on national average cost data. The roofing costs are a fraction of a percent of the total costs of constructing the high school, with the additional costs of the fully adhered membrane leading to an increase of $0.43 \%$ in total costs. Since the roofing costs are mostly insignificant relative to the cost of constructing the building, an increase due to alternative roof systems does not have detrimental impacts on the total cost to the building owner.
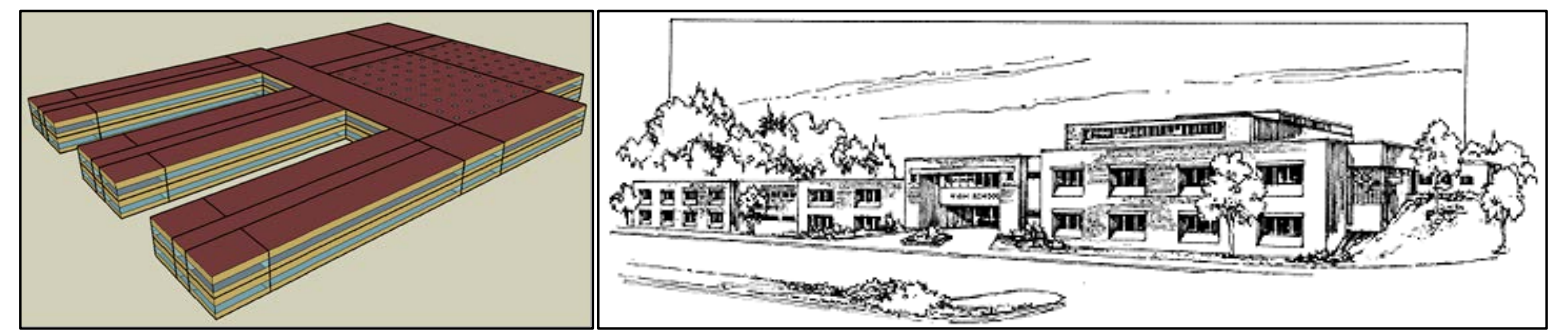

Figure 3-4 Representations of 2-Story High School: DOE (left) ${ }^{17}$ and RS Means (right) ${ }^{18}$

From a retrofitting perspective, other building maintenance, repair, and replacement costs not involving the roof are far more significant than those for re-roofing projects. For example, the cost of installing the windows in the hospital and high school is \$415 000 and \$1.16 million, respectively. Window installation costs are approximately 12 times and 11 times the additional marginal costs of the fully adhered system and the aggregate ballasted system, respectively. Additionally, the fully adhered system will significantly reduce the probability of window damage from wind-borne aggregate due to high winds or tornadoes from the buildings own roof.

\footnotetext{
${ }^{15}$ Source: DOE 2016

${ }^{16}$ Source: RS Means 2016b

${ }^{17}$ Source: DOE 2016

${ }^{18}$ Source: RS Means 2016b
} 


\section{Summary}

This study analyzed the potential impacts from adoption of a proposed change to the IBC that would restrict use of roof aggregate surfacing for Risk Categories III and IV buildings in the tornado-prone region of the U.S., which includes 22 states (with significant portions of 17 states). This study identified the fraction of the roof construction that could be impacted from the restriction on aggregate surfaced roofs, characterized alternatives to aggregate-surfacing, and estimated the costs associated with these alternative roofing systems. Overall, the fraction of roof construction impacted and the associated costs with meeting the proposed change to the IBC on roof aggregate in tornado-prone region appears to be minimal.

\subsection{Potential Impacts of Code Change}

The elimination of potentially millions of windborne missiles from loose aggregate, gravel, and stone surfacing and ballast on roofs of Risk Category III and IV buildings in the tornado-prone region of the U.S. will reduce window and interior damage to these and nearby buildings, and reduce injuries resulting from this damage and from windborne aggregate directly.

The percentage of new roof construction and re-roofing potentially impacted by the proposed code change is identified by combining building stock data by occupancy type and roofing system construction market share data. Based on available data, it is estimated that the code change would potentially impact less than $0.1 \%$ of roof construction in U.S., less than $1.0 \%$ of all non-low-rise residential roof construction in the U.S., less than $0.3 \%$ of roof construction in the tornado-prone region, and less than $3.0 \%$ of all non-low-rise residential roof construction in the tornado-prone region. The previously adopted code change that similarly prohibited aggregate-surfaced roofs in the hurricane-prone region impacted more than four times as much roof construction.

Five roofing systems are considered in the cost analysis of alternative roofing systems, including two built-up roof systems and three single-ply systems, with some systems considered for multiple deck types. For a built-up roof, the system with aggregate surfacing leads to higher installation costs than the alternative system that replaces the aggregate with a cap sheet. For the single-ply systems, the mechanically attached EPDM has the lowest installed cost (assuming an assembly with a steel deck) followed by the aggregate ballasted EPDM system. The fully adhered EPDM system is the most expensive of the three options. These results hold for all 33 cities studied within the tornado-prone region, for which costs were compared using RS Means data

Based on these results, the only new roof construction or re-roofing that would be negatively impacted from a construction cost perspective by the code change are those that would have otherwise installed a ballasted single-ply membrane on a concrete deck. Any installation of BUR systems would realize lower costs using a cap sheet instead of aggregate surfacing, lowering the fraction of Risk Category III/IV buildings that could realize higher costs from the code change 
proposal to under $10 \%$ for both new construction (9.8 \%) and reroofing projects (9.7\%). This is a drop from $0.2 \%$ for new construction and $0.3 \%$ for reroofing to less than $0.2 \%$ of the total building stock in the tornado-prone region and from $2.2 \%$ to $3.0 \%$ to $1.7 \%$ of the non-low rise residential roof construction in the tornado-prone region. Additionally, any roof assemblies with steel decks would cost less by using a mechanically attached EPDM instead of EPDM with aggregate ballast, further lowering the number of roof construction negatively impacted by the change in the code to restrict roof aggregate.

Two example buildings with concrete roof decks were considered to compare the installed costs of the EPDM systems. Comparatively, the additional cost of installing a fully adhered EPDM compared to a ballasted system is $\$ 34615$ for the hospital, or $0.07 \%$, of the overall costs of constructing the hospital (\$51.7 million) while the additional costs for the high school is $\$ 103777$, or $0.43 \%$ of the cost of the high school (\$24.0 million). In either case the additional costs are a small fraction of the total costs of construction.

\subsection{Limitations}

The analysis completed in this study is limited due to currently available data. Assumptions were made, as documented in the report, on interpretation of existing building stock data and roofing construction data. The estimates of potential impacts on new construction and re-roofing, as a percentage of total roofing construction, are upper bound values, since the analysis tended to overestimate the number of buildings that would meet each of the five requirements. The actual values would be smaller, perhaps substantially so. Additionally, cost data can vary widely on a case-by-case basis. Even though RS Means is a well-respected and relied upon resource, RS Means cost data has significant uncertainty because the reported data are averages that may be the combination of widely varying values. The analysis does not include any sensitivity or uncertainty analysis. 


\section{References}

ASCE (2010), ASCE/SEI Standard 7-10: Minimum Design Loads for Buildings and Other Structures, American Society of Civil Engineers (ASCE). Reston, VA.

Crandell, J. H. and Smith, T.L. (2009), Design Method Improvements to Prevent Roof Aggregate Blow -off, Proceedings of Hurricane Hugo 20th anniversary symposium on building safer communities - improving disaster resilience, Applied Technology Council.

Census (2016). Construction Spending - Historical Value Put in Place - Nonresidential Geographic by Division. Accessed September 2016 at https://www.census.gov/construction/c30/historical_data.html.

DOE (2016). Commercial Reference Building for Hospitals. Department of Energy (DOE), accessible at http://energy.gov/eere/buildings/commercial-reference-buildings.

ERA (2016), Standard Attributes of EPDM Systems, EPDM Roofing Association, accessed August 2016 at http://www.epdmroofs.org/what-is-epdm/why-epdm/standard-attributes.

FEMA (2005), Mitigation Assessment Team Report: Hurricane Charley in Florida, FEMA 488, Federal Emergency Management Agency, April 2005. http://www.fema.gov/medialibrary/assets/documents/905.

FEMA (2006), Hurricane Katrina in the Gulf Coast: Mitigation Assessment Team Report, Building Performance Observations, Recommendations, and Technical Guidance, FEMA 549, Federal Emergency Management Agency, July 2006. (see p. 5-63). http://www.fema.gov/media-library/assets/documents/4069.

FEMA (2007), Design Guide for Improving Hospital Safety in Earthquakes, Floods, and High Winds: Providing Protection to People and Buildings, FEMA 577, Federal Emergency Management Agency, June 2007 (see p. 4-123, and 4-126 to 4-140). http://www.fema.gov/media-library/assets/documents/10672.

FEMA (2009), HAZUS-MH MR4, Version 1.4, 2009, Federal Emergency Management Administration, http://www.fema.gov/hazus.

FEMA (2010), Design Guide for Improving School Safety in Earthquakes, Floods, and High Winds, FEMA P-424, Federal Emergency Management Agency, December 2010 (see p. 6-23). http://www.fema.gov/media-library/assets/documents/5264\#.

FEMA (2012), Mitigation Assessment Team Report: Spring 2011 Tornadoes: April 25-28 and May 22 Building Performance Observations, Recommendations, and Technical Guidance, FEMA P-908, Federal Emergency Management Agency, May 2012 (see Tornado Recovery Advisory 6, Appendix F, p. 5). http://www.fema.gov/medialibrary/assets/documents/25810. 
FEMA (2014), HAZUS-MH, Version 3.1, 2014, Federal Emergency Management Administration, http://www.fema.gov/hazus.

FEMA (2015), Safe Rooms for Tornadoes and Hurricanes, Guidance for Community and Residential Safe Rooms, FEMA P-361, Federal Emergency Management Agency, Third Edition, March 2015 (p. A2-5). https://www.fema.gov/medialibrary/assets/documents/3140.

ICC (2006), 2006 International Building Code, International Code Council, Inc.

ICC (2009), 2009 International Building Code, International Code Council, Inc.

ICC (2011), 2012 International Residential Code, International Code Council, Inc.

ICC (2014a), 2015 ICC Performance Code for Buildings and Facilities, International Code Council, Inc.

ICC (2014b), 2015 International Building Code, International Code Council, Inc.

ICC (2014), ICC 500-2014: ICC/NSSA Standard for the Design and Construction of Storm Shelters. International Code Council, Inc.

ICC (2016a), 2016 Group B Committee Action Hearings, Complete Monograph. International Code Council, Inc., accessible at http://media.iccsafe.org/codes/20152017/GroupB/CAH/Complete-Monograph.pdf.

ICC (2016b), Complete Monograph, 2016 Group B Public Comment Agenda,. International Code Council, Inc., accessible at http://media.iccsafe.org/codes/20152017/GroupB/PCH/2016PCA-Complete.pdf.

NIST (2006), Performance of Physical Structures in Hurricane Katrina and Hurricane Rita: A Reconnaissance Report, NIST Technical Note 1476, National Institute of Standards and Technology, June 2006. http://spin1www.nist.gov/customcf/get_pdf.cfm?pub_id=908281\&_ga=1.157485497.2001654181.1 $\underline{385140102}$

NIST (2014), Final Report, National Institute of Standards and Technology (NIST) Technical Investigation of the May 22, 2011, Tornado in Joplin, Missouri, NIST NCSTAR-3, March 2014. https://dx.doi.org/10.6028/NIST.NCSTAR.3.

NOAA (2016a), Summary of 2015 Weather Events, Fatalities, Injuries, and Damage Costs, accessible at http://www.nws.noaa.gov/om/hazstats.shtml.

NOAA (2016b), Weather Fatalities, accessible at http://www.nws.noaa.gov/om/hazstats.shtml. 
NOAA (2016c), 2015 Summary of Hazardous Weather Fatalities, Injuries, and Damage Costs by State, accessible at http://www.nws.noaa.gov/om/hazstats.shtml.

NOAA (2016d), Map of Census Divisions, accessible at http://www1.ncdc.noaa.gov/pub/data/cmb/temp-and-precip/maps/

NOAA (2016e), Enhanced F Scale for Tornado Damage, accessible at http://www.spc.noaa.gov/faq/tornado/ef-scale.html.

NRCA (2015), 2014-2015 NRCA Market Survey, National Roofing Contractors Association (NRCA).

RS Means (2016a), RS Means Online Commercial Building Assembly and Unit Cost Databases, accessed August 2016 at www.RSMeansonline.com.

RS Means (2016b), RS Means Online Square Foot Cost Estimator, accessed August 2016 at www.RSMeansonline.com.

SEAKM (2012), Investigations and Recommendations based on the May 22, 2011 Joplin, Missouri Tornado. Structural Engineers Association of Kansas and Missouri, accessible at http://www.seakm.com/uploads/Joplin_Committee_Report_05262012.pdf. 